This item was submitted to Loughborough's Research Repository by the author.

Items in Figshare are protected by copyright, with all rights reserved, unless otherwise indicated.

\title{
Forecasting the magnitude of potential landslides based on InSAR techniques
}

\section{PLEASE CITE THE PUBLISHED VERSION}

https://doi.org/10.1016/j.rse.2020.111738

\section{PUBLISHER}

Elsevier

VERSION

AM (Accepted Manuscript)

\section{PUBLISHER STATEMENT}

This paper was accepted for publication in the journal Remote Sensing of Environment and the definitive published version is available at https://doi.org/10.1016/j.rse.2020.111738

LICENCE

CC BY-NC-ND 4.0

\section{REPOSITORY RECORD}

Zhang, Y, XM Meng, Tom Dijkstra, CJ Jordan, G Chen, RQ Zeng, and A Novellino. 2020. "Forecasting the Magnitude of Potential Landslides Based on Insar Techniques". Loughborough University. https://hdl.handle.net/2134/13625981.v1. 


\title{
Forecasting the magnitude of potential landslides based on InSAR
}

\author{
techniques \\ NB - this is the author's copy and some deviation with the published material may exist. \\ Zhang Y. ${ }^{1,2}$, Meng X.M. ${ }^{1,2, *}$, Dijkstra T.A. ${ }^{3}$, Jordan C.J. ${ }^{4}$, Chen G. ${ }^{1,2}$, Zeng R.Q. ${ }^{1,2}$, Novellino A. ${ }^{4}$ \\ ${ }^{1}$ MOE Key Laboratory of Western China's Environmental Systems, School of Earth Sciences, Lanzhou University, \\ Lanzhou, 730000, P. R. China \\ 2 Technology \& Innovation Centre for Environmental Geology and Geohazards Prevention, School of Earth \\ Sciences, Lanzhou University, Lanzhou, 730000, P. R. China \\ ${ }^{3}$ School of Architecture, Building and Civil Engineering, Loughborough University, Loughborough, LE11 $3 T U$, \\ $U K$ \\ ${ }^{4}$ British Geological Survey, Nottingham NG12 5GG, UK \\ * Corresponding author (E-mail: xmmeng@lzu.edu.cn)
}

\section{Abstract}

A new method, combining empirical modelling with time series Interferometric Synthetic Aperture Radar (InSAR) data, is proposed to provide an assessment of potential landslide volume and area. The method was developed to evaluate potential landslides in the Heitai river terrace of the Yellow River in central Gansu Province, China. The elevated terrace has a substantial loess cover and along the terrace edges many landslides have been triggered by gradually rising groundwater levels following continuous irrigation since 1968 . These landslides can have significant impact on communities, affecting lives and livelihoods. Developing effective landslide risk management requires better understanding of potential landslide magnitude. Fifty mapped landslides were used to construct an empirical power-law relationship linking landslide area $\left(\mathrm{A}_{\mathrm{L}}\right)$ to volume $\left(\mathrm{V}_{\mathrm{L}}\right)\left(\mathrm{V}_{\mathrm{L}}=0.333 \times \mathrm{A}_{\mathrm{L}}^{1.399}\right)$. InSAR-derived ground displacement ranges from $-64 \mathrm{~mm} / \mathrm{y}$ to $24 \mathrm{~mm} / \mathrm{y}$ along line of sight (LOS). Further interpretation of patterns based on remote sensing (InSAR \& optical image) and field survey enabled the identification of an additional 54 potential landslides $\left(1.9 \times 10^{2} \mathrm{~m}^{2} \leqslant A_{L} \leqslant 8.1 \times 10^{4} \mathrm{~m}^{2}\right)$. In turn this enabled construction of a map that shows the magnitude of potential landslide activity. This research provides significant further scientific insights to inform landslide hazard and risk management, in a context of ongoing landscape evolution. It also provides further evidence that this methodology can be used to quantify the magnitude of potential landslides and thus contribute essential information towards landslide risk management.

Key words: empirical model, time series InSAR, landslide forecasting, landslide volume, risk 1. Introduction

Landslides involve the downward and outward mass movement of slope materials composed of rock, soils, artificial fills, or a combination of these materials (Cruden \& Varnes, 1996). Ongoing population growth, rapidly expanding societies, coupled with gradually progressing environmental (climate) change enhances pressures on the natural environment and results in increased exposure to potentially unstable terrain. Landslides are geohazards that globally result in serious impacts, annually causing tens of billions of US\$ worth of damage and more than 4,300 lives lost (Froude 
and Petley, 2018; Intrieri et al., 2019).

There is a continuing need to develop better tools to enhance the effectiveness of landslide risk management. These tools include mechanisms to identify landslides (historical events and potential landslides), to better understand where these are most likely to occur and what trigger thresholds apply, to evaluate the risk that these events pose and to identify appropriate mitigation interventions. In turn, effective management of these geohazards can then lead to sustainable development that is in harmony with the long-term geomorphological evolution of a particular region (Dai et al., 2002; Guzzetti et al., 2009; Martha et al., 2013).

Recent developments in remote sensing techniques can significantly contribute to developing more effective landslide hazard and risk management. This includes more efficient mapping of landslides using high resolution satellite imagery in a three-dimensional virtual environment and manipulating this digital information to allow further quantitative analyses of landslide parameters (location, size, volume, state of activity; Crosta et al., 2013; Broeckx et al., 2018). In addition, ground deformation on a millimeter scale obtained using time-series InSAR (Interferometry Synthetic Aperture Radar) can be used to update landslide inventory maps and to identify pre-cursor signatures in the landscape that can be used to identify potential landslides (Bovenga et al., 2013; Wasowski and Bovenga et al., 2014; Novellino et al., 2017; Zhang et al., 2018; Ambrosi et al., 2018; Li et al., 2020).

Remote sensing techniques have thus been used successfully to investigate the position and movements of landslides and unstable slopes. However, for disaster risk management it is of greater importance to obtain a measure of the magnitude of potential landslides, e.g. through estimating the volume of material involved (Corominas et al., 2014). This research highlights a feasible route to achieve this, using a case study of the Heitai river terrace in central Gansu Province, China.

Identifying and quantifying the volume of a landslide is possible by measuring the shape and inferring the slip surface geometry of landslides from a range of observational data or using an empirical relationship between geometrical properties (Guzzetti et al., 2009; Malamud et al., 2010; Cui et al., 2018). However, this is generally a laborious and data-intensive assessment that is only realistic for individual events. When a large number of landslides are encountered this soon becomes an unfeasible / uneconomical task and forecasting the volume of potential landslides is even more challenging as there is added uncertainty regarding the landslide geometry and morphology of 
potential slip surfaces.

In this paper, a combined approach is illustrated that uses an empirical model, InSAR techniques and field surveying to evaluate the magnitude of potential landslides (Fig. 1). Firstly, a landslide inventory is established which records the area $\left(\mathrm{A}_{\mathrm{L}}\right)$ and volume $\left(\mathrm{V}_{\mathrm{L}}\right)$ of historic landslides (among other parameters). Subsequently, an empirical relationship between $A_{L}$ and $V_{L}$ is established (cf. Guzzetti et al., 2009). Time-series InSAR data, coupled with geomorphological observations are used to derive polygons showing the location and extent of potential landslides. The empirical relationship is used to convert these areas into volume estimations of these potential landslides. In turn, these estimations enable characterization of the magnitude of the potential events.

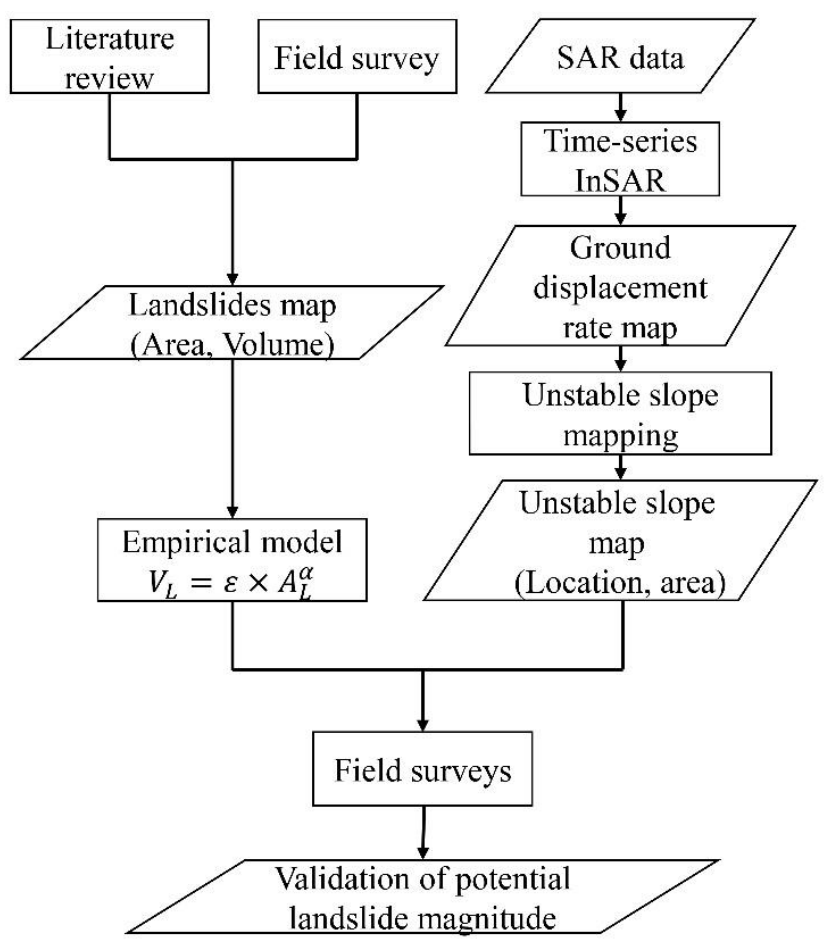

Fig. 1 Workflow for the evaluation of the magnitude of potential landslides at the Heitai terrace, Gansu, China. An initial field survey was employed to verify the boundaries of landslides. Further field surveys enabled validation of the empirical model.

\section{Data and method}

\subsection{Study area}

The Heitai terrace is located $42 \mathrm{~km}$ west of Lanzhou City in central Gansu Province, China (Fig. 2) and is characterized by a flat topography and deeply incised gullies marking the edge of a fluvial terrace landform (the Fourth Terrace of the Yellow River). The terrace covers an area of approximately $12 \mathrm{~km}^{2}$ with a maximum length of $5 \mathrm{~km}$ (in W-E direction) and a width of $3 \mathrm{~km}$ (in N-S direction), at an elevation of approximately $1,730 \mathrm{~m}$ (Peng et al., 2017). The climate is 

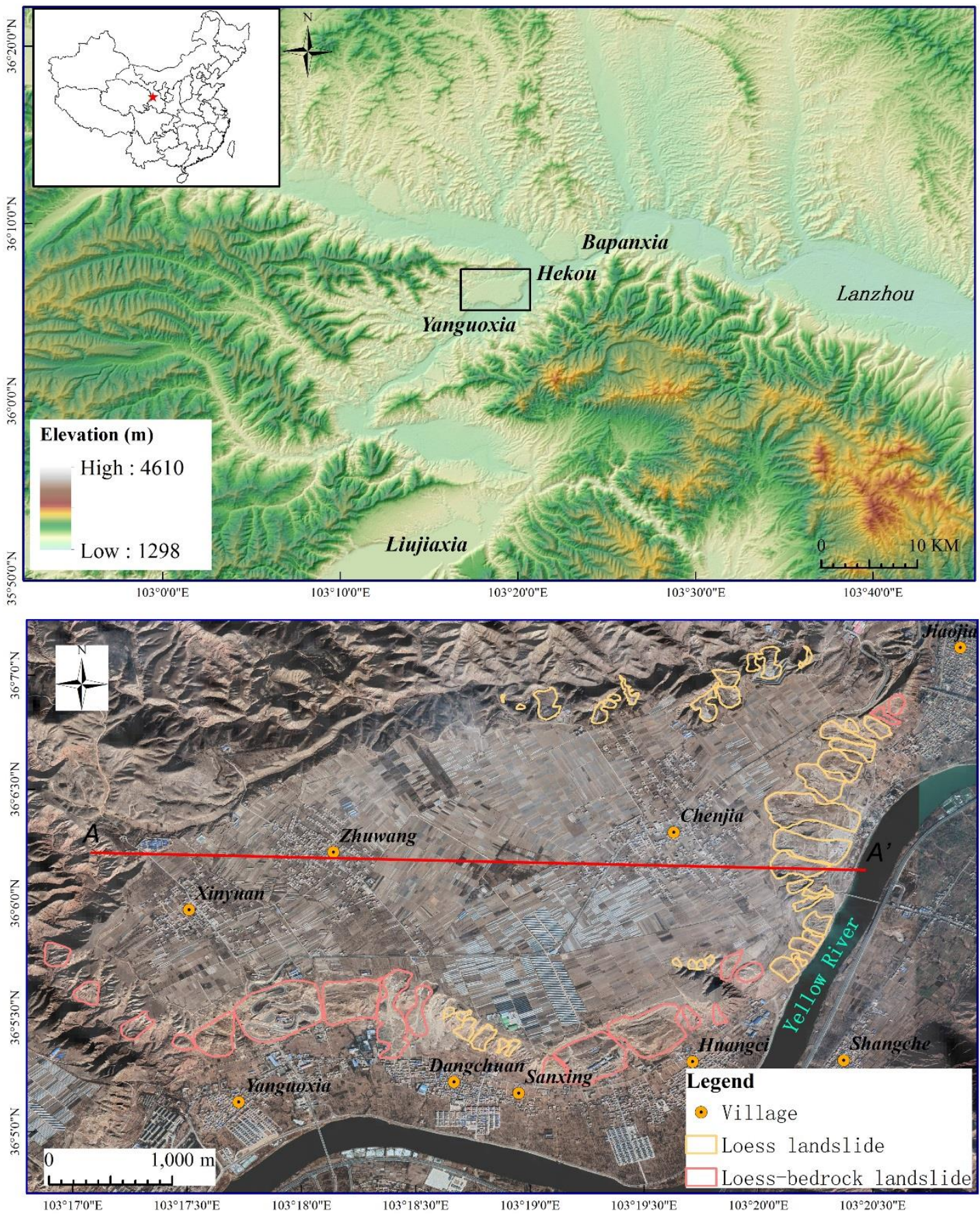

Fig. 2 The Heitai study area (top) and landslides inventory map (bottom). Red line (AA') indicates the location of the geological profile in Fig. 3. The background is Google Earth imagery.

The superficial lithologies comprise a sequence (top to bottom) of aeolian loess (approximately $55 \mathrm{~m}$ thick) overlying clay-rich loess (approx. $8 \mathrm{~m}$ thick), fluvial gravel (particle size of 2-10 cm) 
mixed with sands (comprising mainly quartz; approx. $5 \mathrm{~m}$ thick). The underlying bedrock surface is represented by sequences of mudstones and sandstones dipping $11^{\circ}$ to the SE (Zeng et al., 2016) (Fig. 3).

From 1968, irrigation systems were established to support agricultural activities developed on Heitai terrace. Approximately 5 times per year the terrace is irrigated resulting in a process of ground water recharge that has raised the groundwater level by $20 \mathrm{~m}$ at an average annual rate of $0.18 \mathrm{~m}$ (Xu et al., 2014). Raising groundwater levels induced more than 107 loess-related landslides since 1969, destroying buildings, facilities and causing multiple fatalities (Dijkstra et al., 1994; Zeng et al., 2016). Presently, some 50 landslide signatures are still visible as older events are superseded by later ones (Fig. 2).

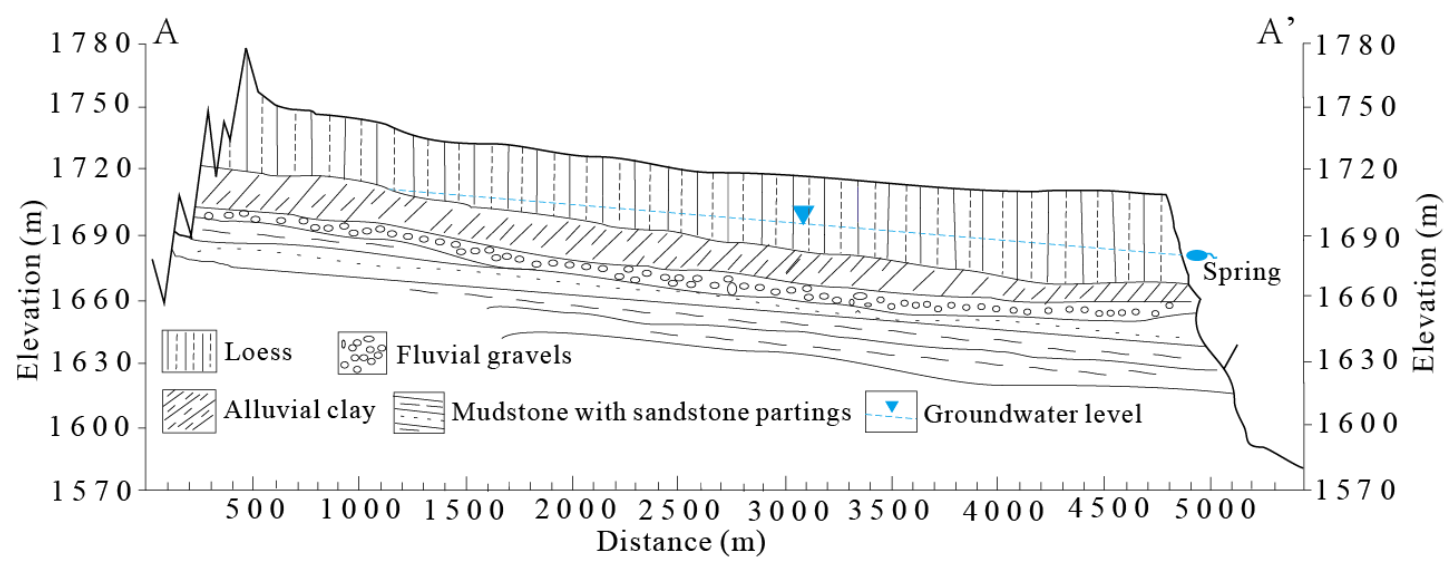

Fig. 3 Geological cross-section of Heitai terrace. The locations are shown in Fig. 2 (line AA'). (modified from Peng et al., 2016)

\subsection{Landslide mapping}

A database of the geometrical characteristics for landslides along the Heitai terrace was collated by Peng et al. (2017). It records basic geometry (e.g., length, width, affected area, volume) of different landslides types. This database was expanded using detailed information on individual landslides from the literature (Xu et al., 2008; Xu et al., 2012; Dong et al., 2013; Zhang et al., 2017). In addition, information from all available maps and tables in the literature above were digitized and incorporated into the Heitai landslide inventory. Further 3D interpretation of satellite images from Google Earth, complemented by extensive field surveys, has resulted in improved approximation of the volume for each of the 50 landslides.

\subsection{Relationship between area and volume}

Recent research proposes empirical models to link landslide area $\left(\mathrm{A}_{\mathrm{L}}\right)$ to landslide volume $\left(\mathrm{V}_{\mathrm{L}}\right)$ for different landslide types and for a range of physiographic and climatic settings (e.g. Guzzetti et 
al., 2009; Qiu et al., 2017; Zhuang et al., 2018). These models are relevant for a broad range of landslide areas $\left(2 \times 10^{0} \mathrm{~m}^{2}<\mathrm{A}_{\mathrm{L}}<3.9 \times 10^{10} \mathrm{~m}^{2}\right)$ and describe the relationship between $\mathrm{A}_{\mathrm{L}}$ and $\mathrm{V}_{\mathrm{L}}$ in a distinct power law:

$$
V_{L}=\varepsilon \times \mathrm{A}_{L}^{\alpha}
$$

where $\mathrm{A}_{\mathrm{L}}\left(\mathrm{m}^{2}\right)$ is area of source section of landslide, $\mathrm{V}_{\mathrm{L}}\left(\mathrm{m}^{3}\right)$ is volume of landslide, $\varepsilon$ and $\alpha$ are curve-fitting parameters.

The construction of these empirical relationships is based on the analysis of detailed landslide inventories that contain relevant information including location, length, width, area, volume and landslide type. Establishing a comprehensive inventory requires an integrated approach involving essential components including field measurements, remote sensing (e.g. aerial photograph interpretation), geomorphological surveys, geotechnical investigations and geophysical surveys (Guzzetti et al., 2009; Tseng et al., 2013; Chen et al., 2014; Cui et al., 2018). Most of the landslide geometric properties can be retrieved by interpreting high-resolution aerial photographs, satellite images and DEMs (Digital Elevation Model) and further analysis in a GIS environment can assist with the establishment of a classification of landslide susceptibility.

\subsection{Potential landslides mapping using time series InSAR}

Synthetic Aperture Radar (SAR) is a coherent radar system where electromagnetic waves backscattered from the Earth's surface are collected, usually from a spaceborne platform. The conventional DInSAR (Differential Interferometric Synthetic Aperture Radar) method uses two or more SAR images covering the same area and acquired at different times to determine ground displacement from phase differences detected during successive SAR acquisitions (Hanssen, 2001; Ferretti et al., 2007). DInSAR can be affected by temporal decorrelation effects and atmospheric noise (Wasowski and Bovenga, 2014), and various approaches of time series analysis of SAR data have been developed to mitigate these issues (Osmanoğlu et al., 2016 and references therein). The decorrelations and atmospheric disturbances are mitigated by identifying radar targets where time series of ground deformation can be extracted (Ferretti et al., 2001).

Time series InSAR algorithms can detect surface ground deformation with high precision (mm) for large areas and produce ground displacement rate maps for investigating landslide and potential landslides (Wasowski \& Bovenga, 2014). In particular, the Small Baseline Subset (SBAS) technique has been used in this work. The SBAS algorithm uses distributed scatterers identified by imposing 
constraints on the spatial and temporal baselines of SAR data used for the interferograms in order to reduce orbital errors and decorrelation noise (Berardino et al., 2002). The SBAS technique was used to process 42 ascending Sentinel 1A images and obtain the ground displacement map. The images were acquired from $14^{\text {th }}$ October 2014 to $7^{\text {th }}$ May 2017, with the central incident angle of $44.4^{\circ}$ from the vertical. The 1-arcsecond ( $\left.\sim 30 \mathrm{~m}\right)$ Shuttle Radar Topography Mission (SRTM) data from the United States Geological Survey (USGS) was used to remove the topographic phase and geocode the InSAR products. With a perpendicular baseline threshold of $160 \mathrm{~m}$ and a temporal baseline of 80 days, 114 interferograms were generated (Fig. 4).

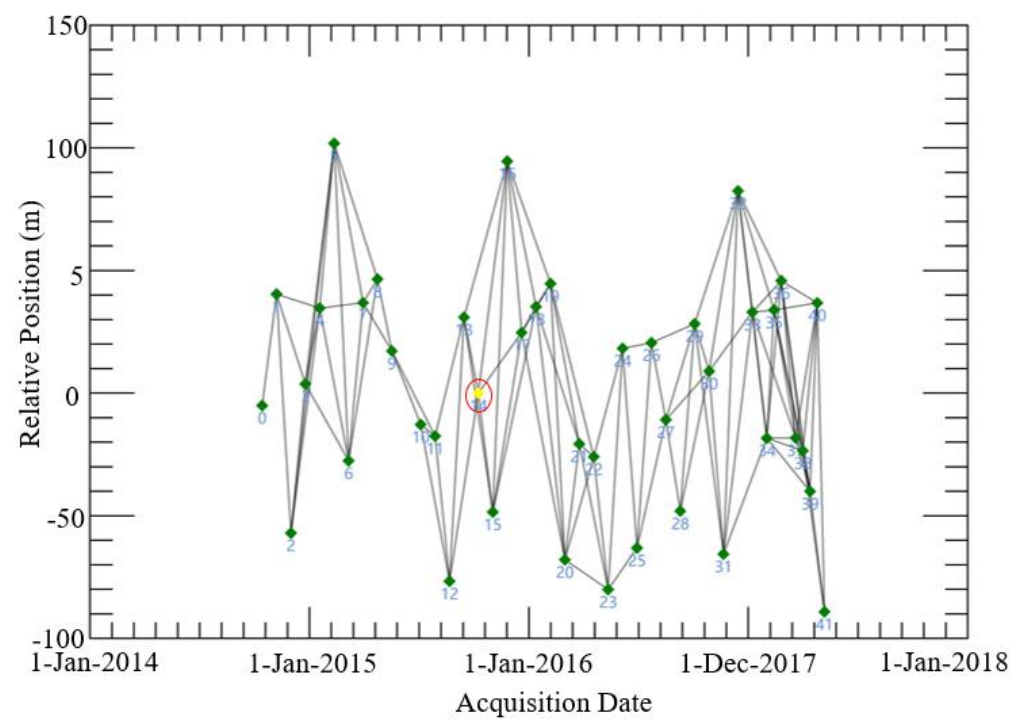

Fig. 4 Spatial-temporal distribution of interferogram formation. Green dots and black lines represent images and interferometric pairs, respectively. The yellow dot in the red circle is the master image used for the co-registration.

Once the spatial distributions of surface displacement are established, further interpretation of the observed pattern can lead to identification of displacement rate threshold to identify potential landslides depending on the lithological characteristics, failure mechanisms, sensor measurement precision and the investigation objectives (Wasowski \& Bovenga, 2014). These thresholds are usually informed by statistical parameters such as standard deviation of displacement rates (Herrera et al., 2013; Bonì et al., 2016; Zhang et al., 2018).

\section{Results}

\subsection{Dependency of volume on area}

Landslide dimensions are estimated using a $10 \mathrm{~cm}$ resolution Digital Elevation Model (DEM), 3-D Laser Scanning by Peng et al. $(2016,2017)$ and refined by field investigations in this work. For 
the Heitai region, landslide areas cover a range from $9.6 \times 10^{2} \mathrm{~m}^{2}$ to $2.1 \times 10^{5} \mathrm{~m}^{2}$ and landslide volumes range from $9.1 \times 10^{2} \mathrm{~m}^{3}$ to $6.1 \times 10^{6} \mathrm{~m}^{3}$. Landslide magnitude can be expressed as the base 10 logarithm of landslide volume ( $c f$. Malamud et al, 2004) resulting in landslide magnitudes ranging from 2 to 6 .

The area $\left(\mathrm{A}_{\mathrm{L}}\right)$ and volume $\left(\mathrm{V}_{\mathrm{L}}\right)$ of 50 historical landslides were plotted in a log-log graph (Fig. 5) and this shows a clear linear relationship between $A_{L}$ and $V_{L}$ across multiple orders of magnitude. Fitting a regression similar to the one proposed in Guzzetti et al. (2009) enables the derivation of the following formula:

$$
\mathrm{V}_{\mathrm{L}}=0.333 \times \mathrm{A}_{\mathrm{L}}^{1.399} \quad\left(\mathrm{R}^{2}=0.795\right)
$$

where the landslide volume $\left(\mathrm{V}_{\mathrm{L}}\right)$ can be calculated on the basis of the observed landslide area $\left(\mathrm{A}_{\mathrm{L}}\right)$ for this source area of landslides in the Heitai terrace.

The bivariate kernel density estimation for the landslide data points in Fig. 5 shows that the best fit goes through the highest density and this suggests a good relationship to empirical model. Moreover, the upper and lower 95\% prediction intervals (dashed red lines in Fig. 5) show that the scatter of the empirical data around the regression line is limited. Only one record falls outside the intervals indicating a robust empirical relationship.

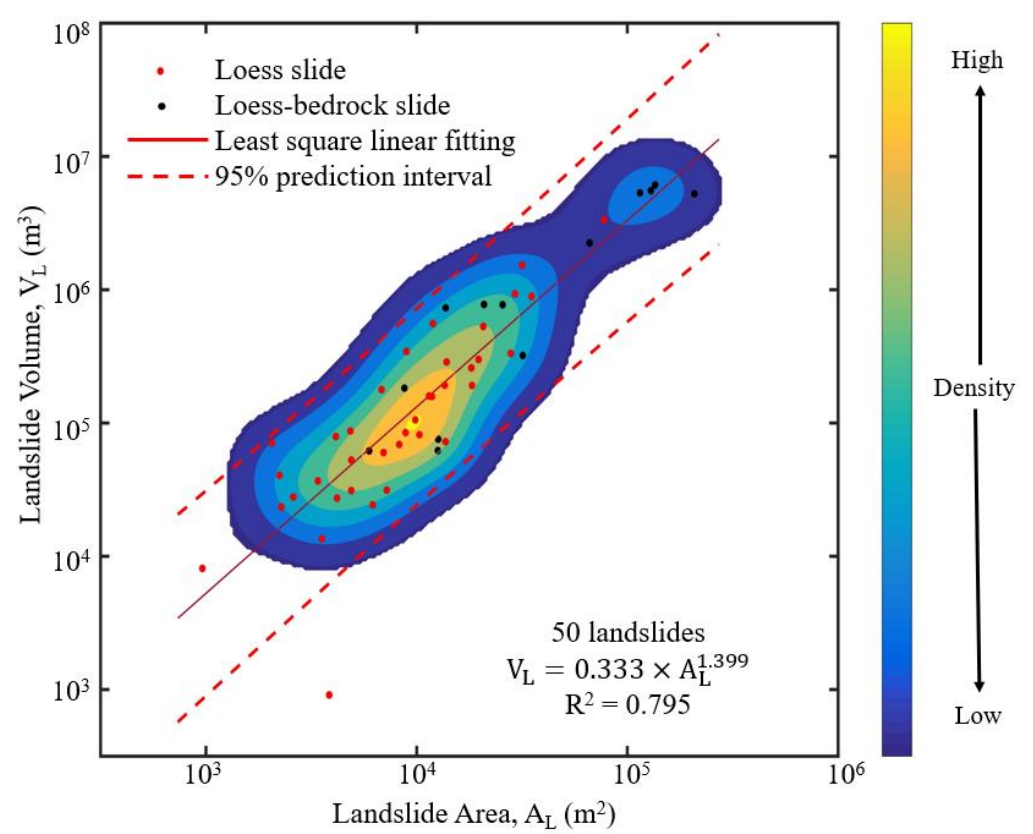

Fig. 5 Empirical model for landslides obtained through a literature review and field survey. Dots portray the area, $A_{L}\left(x\right.$-axis, $\left.m^{2}\right)$, and volume, $V_{L}\left(y\right.$-axis, $\left.m^{3}\right)$, of 50 landslides. The solid red line represents the best fit obtained, adopting a least square linear fitting technique. Dashed red lines show $95 \%$ confidence intervals. Colours indicate density of points obtained through bivariate kernel density estimation. 
There are two observations that need to be considered in this relationship: the areal boundary and the type of the mapped landslides. Five types of landslide are included in the landslide inventory: loess-bedrock planar (translational) slide, loess-bedrock (complex) slide, loess flow slide, loess slides and loess flow (Peng et al., 2017). Considering the material of the landslide body, landslides were classified into loess and loess-bedrock slide. The morphology of the slip plane, and the postfailure deformation behaviour both vary. However, these landslides have similar failure initiation mechanisms, with sliding initiated in a source area along the upper parts of the river terrace escarpment (Fig. 6).

Where the slip surface is positioned largely along a loess-bedrock contact surface it tends to form a major planar slip surface. Where most of the slip surface is located in loess a rotational slip surface is common. For both these types of landslide the post-failure deformation is characterized by a rapid disintegration of the slide mass and a transition to flow-like movement with long runout distances. The potential area that is covered by the landslide bodies is influenced by factors such as antecedent moisture (groundwater table position), the local difference between minimum and maximum elevation, dominant lithology (loess, bedrock) and roughness of the ground over which a landslide travels; a detailed geo-mechanical analysis falls outside the present study. The combination of area and volume for the different types (loess slide \& loess-bedrock slide) of landslides encountered at the Heitai did not affect the empirical relationship shown in Fig. 5.
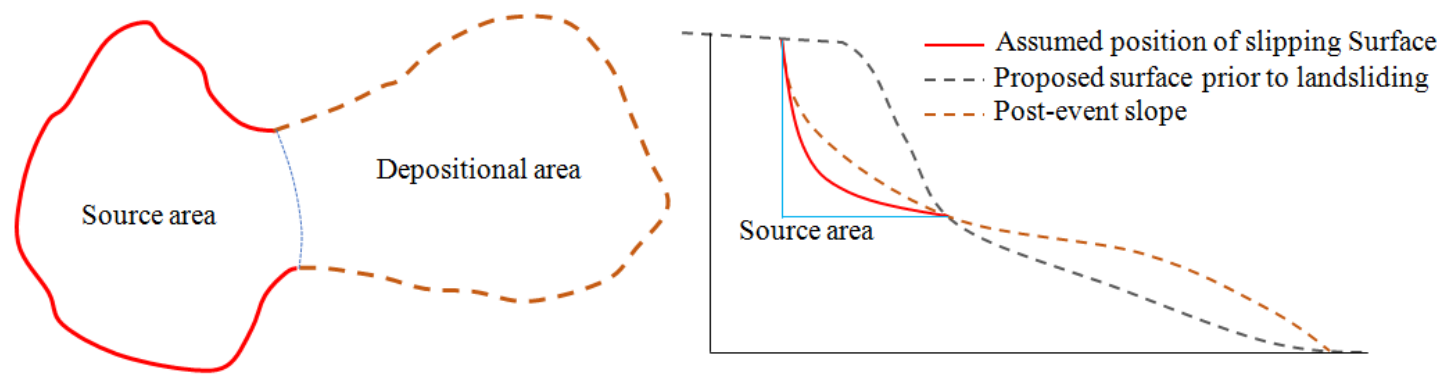

Fig. 6 (Left) Conceptual diagram of typical Heitai landslide where the red line is the outline of the landslide and includes the source and depositional areas. (Right) A schematic section through a landslide showing the original slope profile, the post-event slope and the assumed position of the slip surface.

\subsection{Landslide mapping by SBAS-InSAR}

The mean displacement rate map obtained from the ascending Sentinel datasets is illustrated in Fig. 7. A higher threshold for different temporal coherence for extracting CTs (coherent targets) provides a smaller standard deviation of displacement rates of CTs, but a lower density introduces gaps of ground deformation for many slopes along the edges. Optimization of threshold versus 
density resulted in a coherence threshold of 0.35 corresponding to a standard deviation of velocity $(5 \mathrm{~mm} / \mathrm{y})$ indicating a statistically acceptable accuracy of the InSAR results. At the same time, this coherence threshold provides an appropriate density of CTs covering the majority of slopes along terrace edges (Fig. 7). Therefore, the surface displacement rates are extracted for points with a temporal coherence threshold $\geq 0.35$ to provide sufficient pixel density for mapping. A total of 157,434 CTs cover the clipped SAR image (clipped to the terrace landform; approximate area 65 $\mathrm{km}^{2}$ ) providing an average density of 2,399 $\mathrm{CTs} \mathrm{km}^{-2}$. The density of CTs is deemed sufficient to detect the movements of all slopes along the terrace edge, and map the boundaries of potential landslides more accurately. The displacement was extracted along the Line-Of-Sight (LOS) where negative values represent ground motion away from the satellite, and positive values represent movement towards the satellite. The CTs completely cover the gullies and slopes due to the large incidence angle of LOS and higher temporal resolution of Sentinel 1A data (at least 12 days) with respect to some SAR platforms, such as Envisat ASAR (at least 35 days), ALOS PALSAR (at least 46 days), RADARSAT-2 (at least 24 days) and COSMO-SkyMED (at least 16 days) (Fig. 4 \& 7).

Displacement rates between $+24 \mathrm{~mm} / \mathrm{y}$ and $-64 \mathrm{~mm} / \mathrm{y}$ were detected on the Heitai terrace and slopes along the edge (Fig. 7). Most of the largest deformation rates in the northern, southwestern and southeastern sectors show displacement rates in excess of $-60 \mathrm{~mm} / \mathrm{y}$ which is consistent with previous findings (Xu et al., 2014; Peng et al., 2017; Shi et al., 2019).

The displacements were verified by a series of field survey. The Heitai is a long-term field observatory that is subject to a large number of surveys each year (e.g. Guo et al., 2015; Zeng et al., 2016). The mean LOS velocity of up to $-30 \mathrm{~mm} / \mathrm{y}$ in the western sector of the terrace represents subsidence associated with the development of a large number of sinkholes, consistent with subsidence rates observed in previous decades (Guo et al., 2015). In the central sector of the terrace, the displacement rates vary from $-10 \mathrm{~mm} / \mathrm{y}$ to $-20 \mathrm{~mm} / \mathrm{y}$ and indicate ground subsidence which has caused many cracks in buildings (average width $\sim 2 \mathrm{~cm}$ ) in the past 3 to 4 years. Most of the displacement rates from $10 \mathrm{~mm} / \mathrm{y}$ to $20 \mathrm{~mm} / \mathrm{y}$ indicate landslide deposits that are still active. It is notable that deformation rates exceeding $20 \mathrm{~mm} / \mathrm{y}$ in the northern and southern edges of the terrace are consistent with the location of many fresh cracks which have widths of several tens of centimeters (Fig. 7). The detailed field surveys highlighted that small sinkholes, crack and signs of subsidence corresponded with displacement rates of approximately $\pm 5 \mathrm{~mm} / \mathrm{y}$. Displacement rates 
252 greater than $\pm 10 \mathrm{~mm} / \mathrm{y}$ showed much larger features including large (> $150 \mathrm{~mm}$ width) and long 253 (tens of meters) cracks, particularly along the terrace edge. As a consequence, a stability threshold 254 of $\pm 10 \mathrm{~mm} / \mathrm{y}$ has been chosen to identify potential landslide areas. If the LOS displacement is 255 projected in the direction of the steepest slope (e.g. following the approach of Cigna et al. (2013) 256 and Herrera et al. (2013)), most of the CTs would have larger displacement rates and the stability 257 threshold defined for mapping would increase correspondingly. This projection could potentially 258 result in CTs returning positive values and these would generally be discarded, resulting in a lower 259 density of CTs (e.g. Herrera et al. (2013) and Zhang et al. (2018)). For this research it was therefore 260 decided to use the LOS displacement as this ensured a higher density of CTs and enabled more 261 detailed mapping of unstable slopes. 


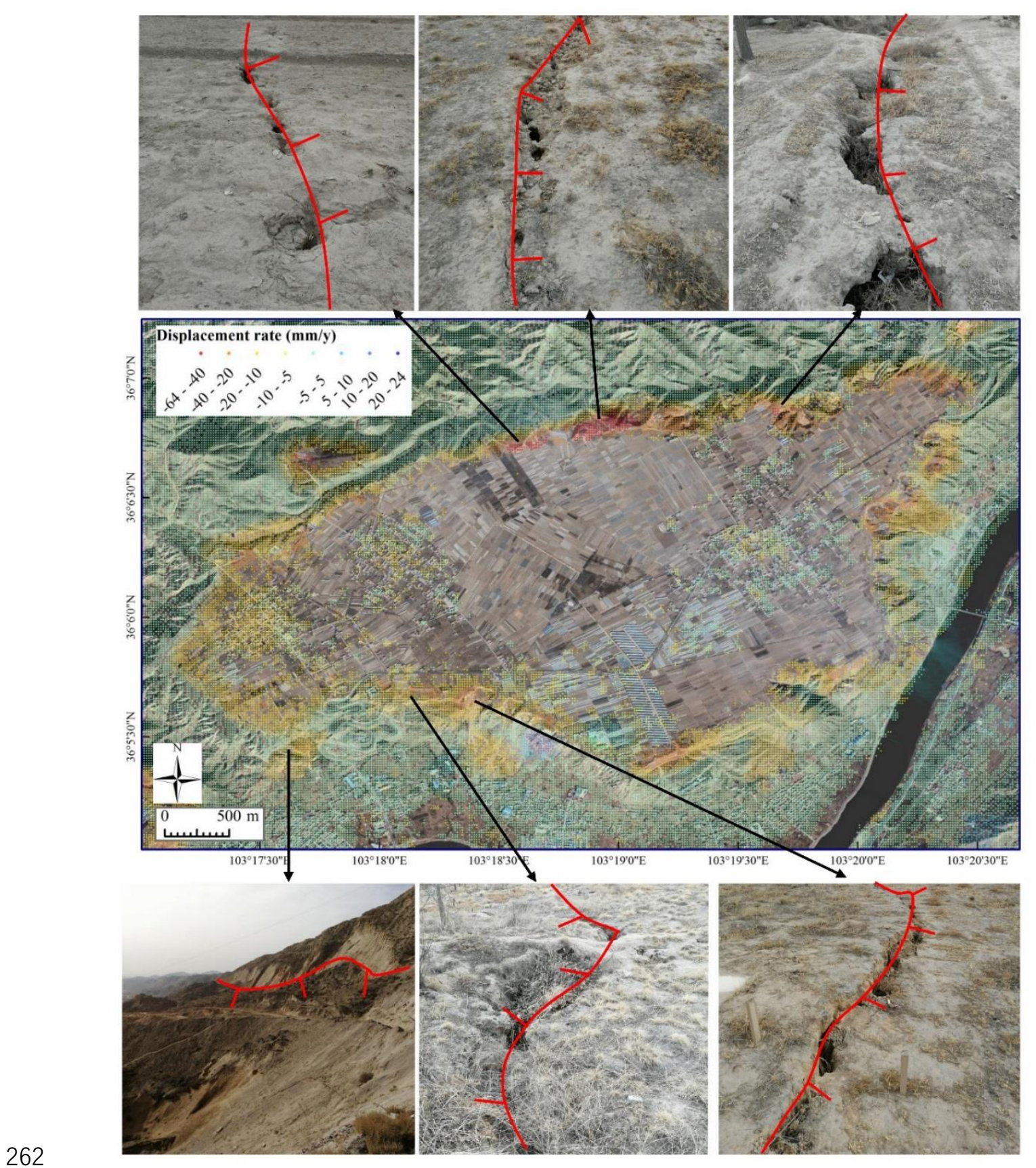

Fig. 7 Mean displacement rates estimated by SBAS and demonstrated by field survey for cracks and scarps investigation. Photographs on the top and below are cracks and scarps along the edge of terrace.

Distribution of ground deformation and knowledge of slope instability in the Heitai region enabled identification and mapping of potentially unstable areas. The potential landslide inventory was prepared using the displacement rates from InSAR, available satellite imagery (Google Earth), aerial photos and topographic data at high spatial resolution. Specifically, Google Earth provides a three-dimensional virtual environment which can be used to view slope geometry.

A minimum number of CTs should be considered to ensure that detected displacements are 271 indicative of an impending landslide. Considering the area of mapped historical landslide $\left(9.6 \times 10^{2}\right.$ 
$\left.\mathrm{m}^{2}<\mathrm{A}_{\mathrm{L}}<2.1 \times 10^{5} \mathrm{~m}^{2}\right)$, original pixel spacing of Sentinel $1 \mathrm{~A}(\sim 14 \mathrm{~m}$ in azimuth and $\sim 4 \mathrm{~m}$ in range $)$

273 and the CTs density over the area of study, the minimum threshold to establish displacement rates 274 is set at 4 CTs within an unstable slope polygon in this case.

Geomorphological interpretation coupled with detailed field surveying of ground deformation and crack development along the terrace edges of the Heitai enabled the establishment of a set of criteria for the recognition and mapping of potential landslides in this study area

- the lower margin of a potential landslide polygon appears along or just above the interface total area of potential landslides is $9.8 \times 10^{5} \mathrm{~m}^{2}$.

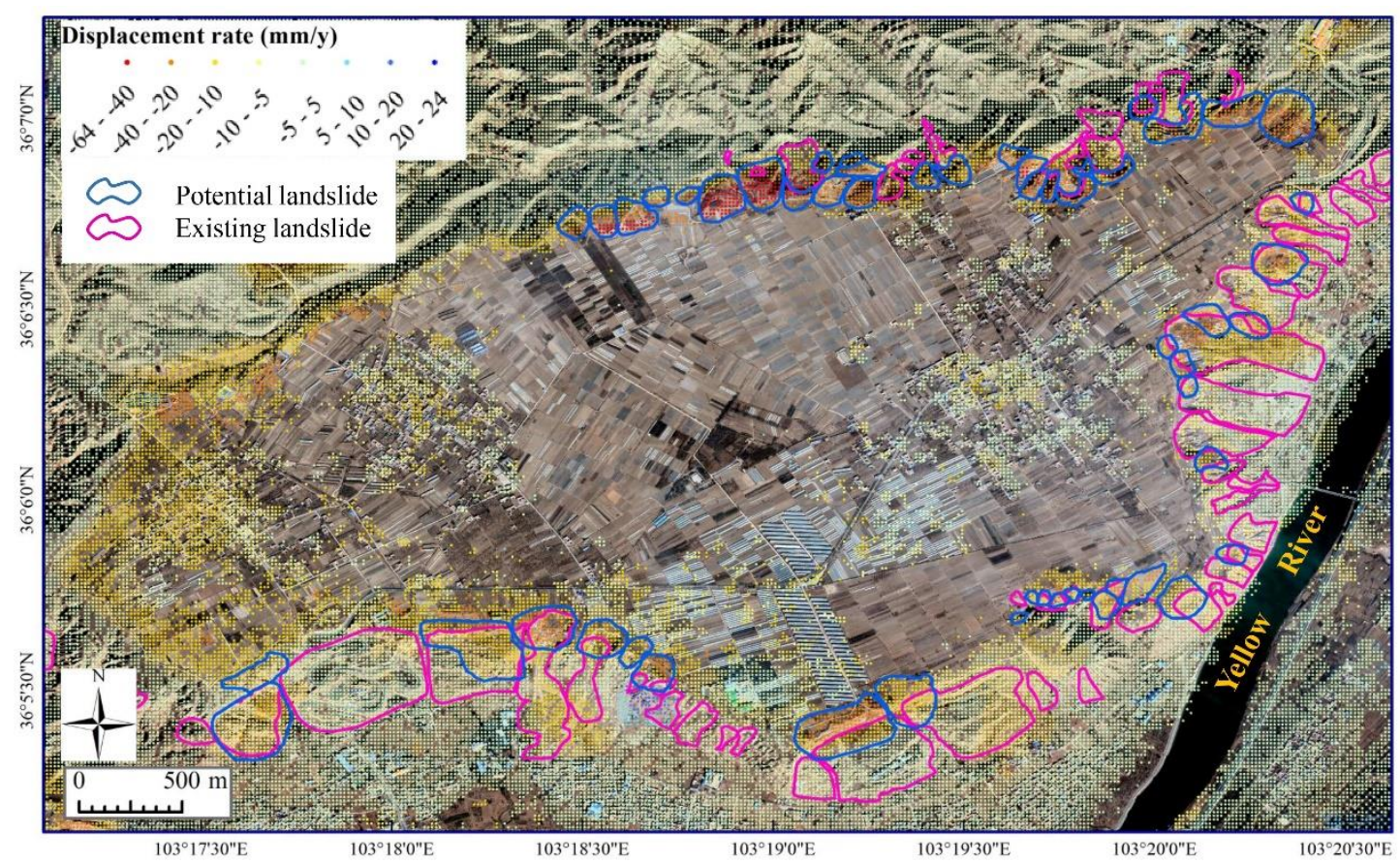

Fig. 8 Potential landslides mapped based on displacement rate map. The background is Google Earth 
294 (Fig. 9) shows that most of the slopes with $V_{s}$ greater than $30 \mathrm{~mm} / \mathrm{y}$ are located along the northern pre-failure strains appear to indicate that along this northern edge of the Heitai terrace a new phase of intensive landslide activity is imminent (Fig. 9).

298

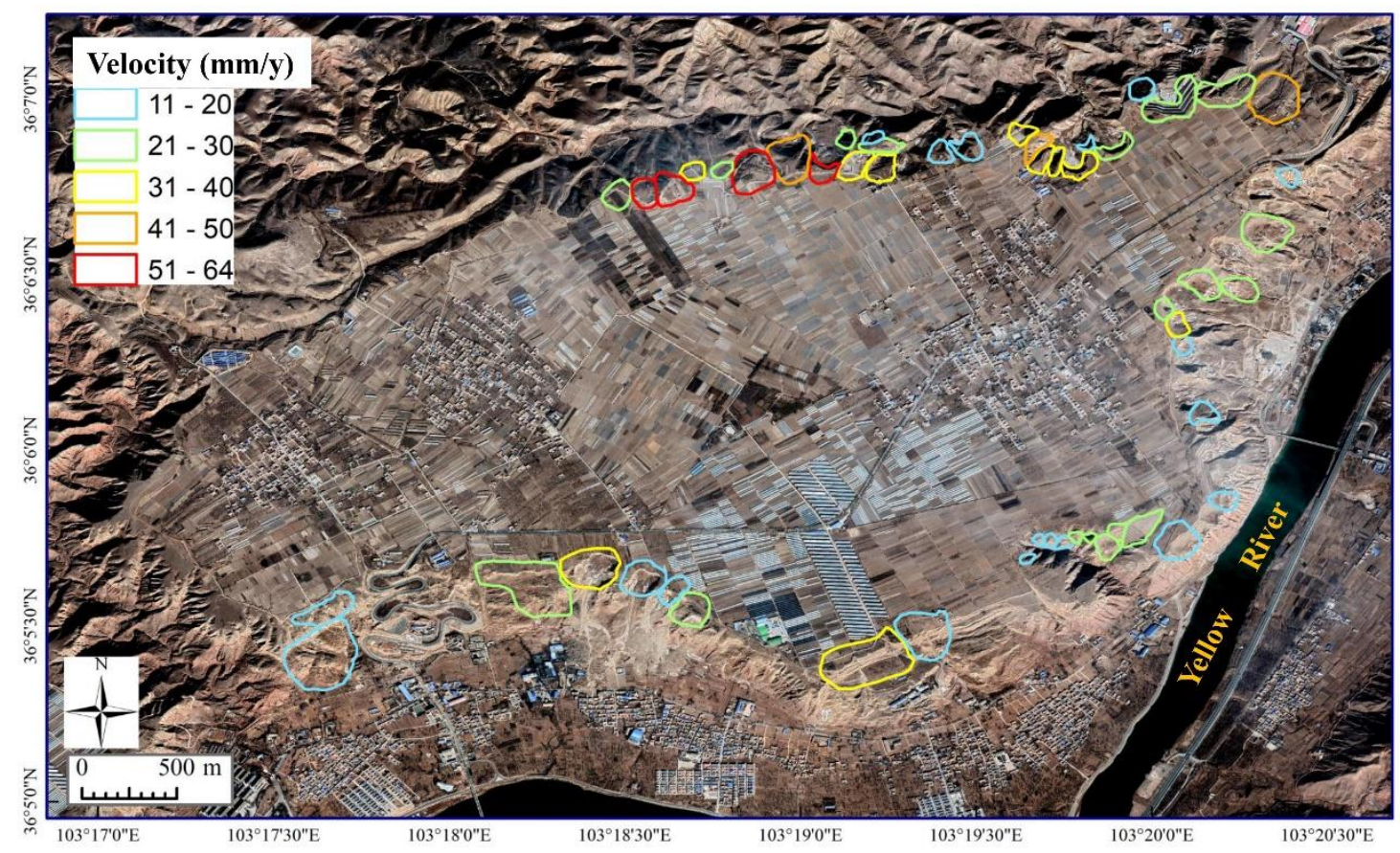

Fig. 9 Displacement rates of potential landslides in Heitai terrace. The colours of outlined polygons indicate the mean LOS velocity of CTs inside the polygon. The background is Google Earth imagery.

\subsection{Potential landslide volume}

The empirical relationship shown in (2), generated using the SBAS-derived area as input, was used to calculate the volume of individual potential landslide $\left(V_{P}\right)$ (Table 1, Fig. 10, Fig. 11). Before $7^{\text {th }}$ May 2017, the 54 mapped potential landslides range in volume from $1.3 \times 10^{4} \mathrm{~m}^{3}$ to $2.49 \times 10^{6} \mathrm{~m}^{3}$, with the most numerous failures in the range $1.0 \times 10^{5} \mathrm{~m}^{3}<\mathrm{V}_{\mathrm{P}} \leq 1.0 \times 10^{6} \mathrm{~m}^{3}$. However, 6 potential landslides with volume greater than $1.0 \times 10^{6} \mathrm{~m}^{3}$ account for the largest volume percentage in the total volume of all potential landslides. The results confirm the important contribution of large landslides to the total volume of landslide material in an area. The ratio between the mapped $A_{P}$ and the computed $V_{P}$ was used to calculate the thickness of potential landslides. For the mapped potential landslides, the landslide volume totaled $\mathrm{V}_{\mathrm{LT}}=2.0 \times 10^{7} \mathrm{~m}^{3}$, with a total area of $\mathrm{A}_{\mathrm{LT}}=9.8 \times 10^{5}$ $\mathrm{m}^{2}$, corresponding to an average thickness of potential landslide material for the Heitai terrace of 20 
$\mathrm{m}$. The thickness of the individual landslide ranges from $7 \mathrm{~m}$ to $30 \mathrm{~m}$, with an average of $15 \mathrm{~m}$.

313 Table 1 Statistics of the volume of forecasted potential landslides. $V_{R}$ indicates the volume range of potential landslides. $\mathrm{N}$ indicates the number of potential landslides in the volume range. $\mathrm{P}_{\mathrm{TN}}$ is the percentage of $\mathrm{N}$ in the total number of potential landslides. $\mathrm{P}_{\mathrm{TA}}$ is area percentage of potential landslides with same magnitude in the total area of potential landslides. $\mathrm{P}_{\mathrm{TV}}$ is volume percentage of potential landslides with same magnitude in the total volume of potential landslides.

\begin{tabular}{ccccc}
\hline $\mathrm{V}_{\mathrm{R}}\left(\mathrm{m}^{3}\right)$ & $\mathrm{N}$ & $\mathrm{P}_{\mathrm{TN}}(\%)$ & $\mathrm{P}_{\mathrm{TA}}(\%)$ & $\mathrm{P}_{\mathrm{TV}}(\%)$ \\
\hline $1.3 \times 10^{4} \leqslant \mathrm{~V}_{\mathrm{P}} \leqslant 1.0 \times 10^{5}$ & 16 & 30 & 17 & 4 \\
\hline $1.0 \times 10^{5}<\mathrm{V}_{\mathrm{P}} \leqslant 1.0 \times 10^{6}$ & 32 & 59 & 45 & 45 \\
\hline $1.0 \times 10^{6}<\mathrm{V}_{\mathrm{P}} \leqslant 2.49 \times 10^{6}$ & 6 & 11 & 38 & 51
\end{tabular}

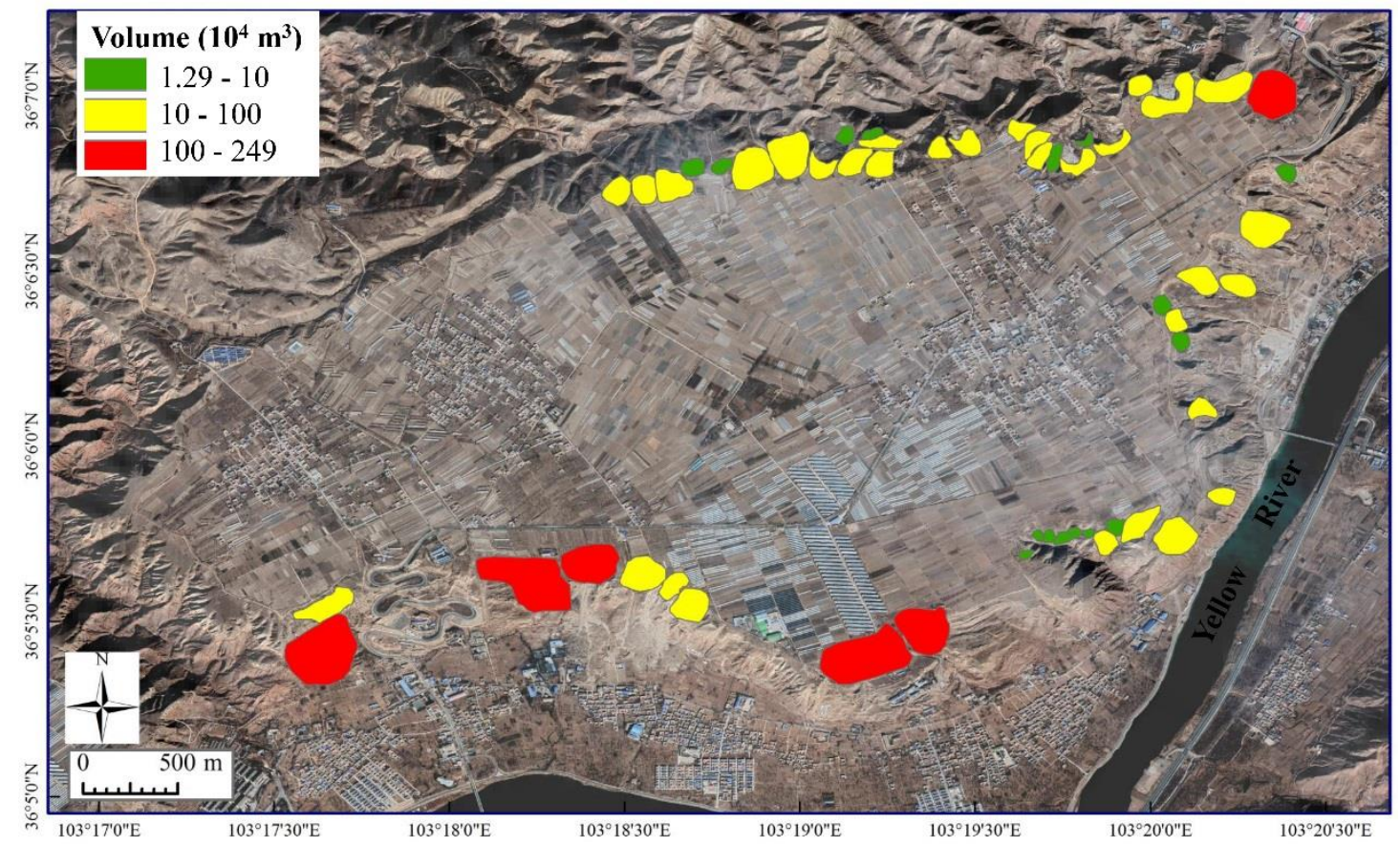

Fig. 10 The volume of potential landslides calculated based on empirical relationship. The colours of polygons indicate the volume and magnitude of potential landslides. 


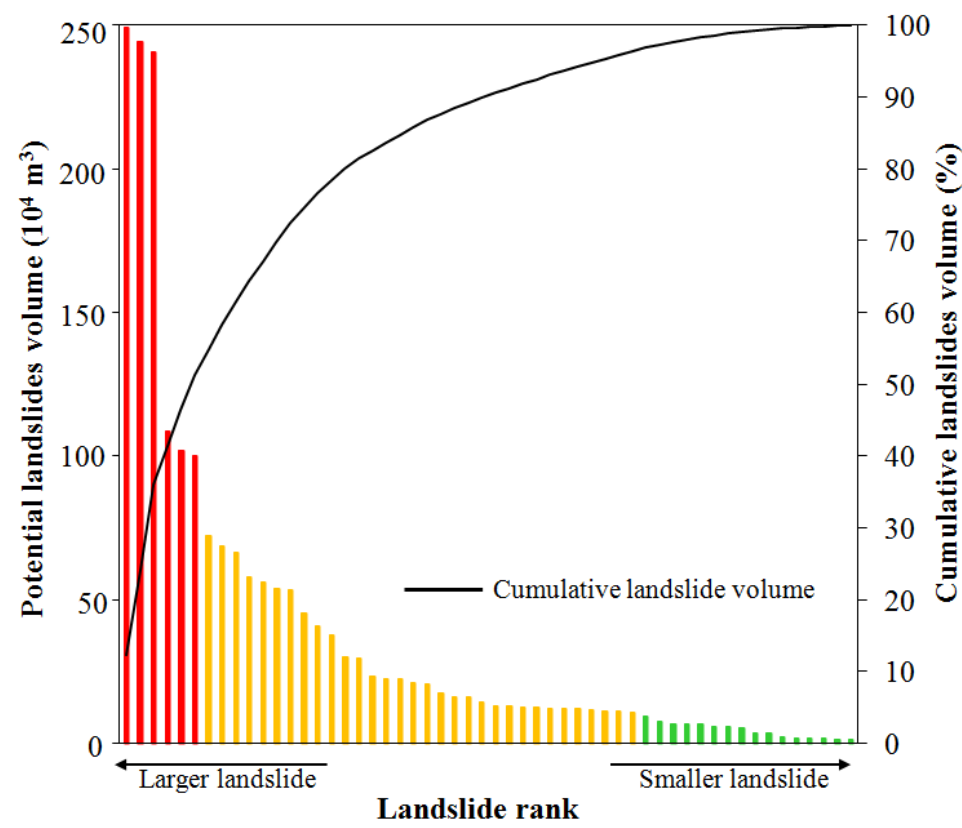

Fig. 11 Landslide volume versus landslide rank. The column colour corresponds to landslide volume classes shown in Fig. 10.

\subsection{Pre-failure strains of potential landslides}

The movement of a landslide can be divided into four stages: 1) the pre-failure stage, 2) the onset of failure, 3) the post-failure stage and 4) the reactivation stage (Leroueil, 2001). The prefailure stage is crucial to forecast the time of slope failure and is controlled mostly by deformations due to local variation in stress, creep and progressive failure (Saito, 1969; Voight, 1989; Leroueil, 2001; Federico et al., 2012; Carlà et al., 2019; Intrieri et al., 2019).

For brittle materials that have very little or no discernable pre-failure strain it is difficult to detect the pre-cursors to failure. However, the pre-failure strains of loess deposits in Heitai terrace are well documented and observations from both laboratory tests and field investigations have shown that loess deposits can accumulate substantial pre-failure strains as a consequence of gradually accumulating micro-shears in the loess fabric (Zhang and Wang, 2017; Shi et al., 2019).

Following on from the early works on pre-failure strain by Saito (1965) and Voight (1988), it has been proposed that extrapolation of the reciprocal of displacement rate (velocity) can indicate when a material would fail. However, the mobilization of pre-failure strains responds to varying stress and moisture conditions in these materials providing a potentially complex pattern of strain before accelerating until failure. Pre-failure strain can be summarized into three sub-phases (Saito, 1969; Voight, 1989; Petley et al., 2005; Federico et al., 2012) (Fig. 12):

- Decelerating displacement where the displacement starts at a rapid rate and slows with 
time;

- Steady displacement where the displacement has a relatively uniform rate;

- Accelerating displacement where the displacement has an accelerated rate and

\section{Fig. 12 Idealized pre-failure strain model} terminates.

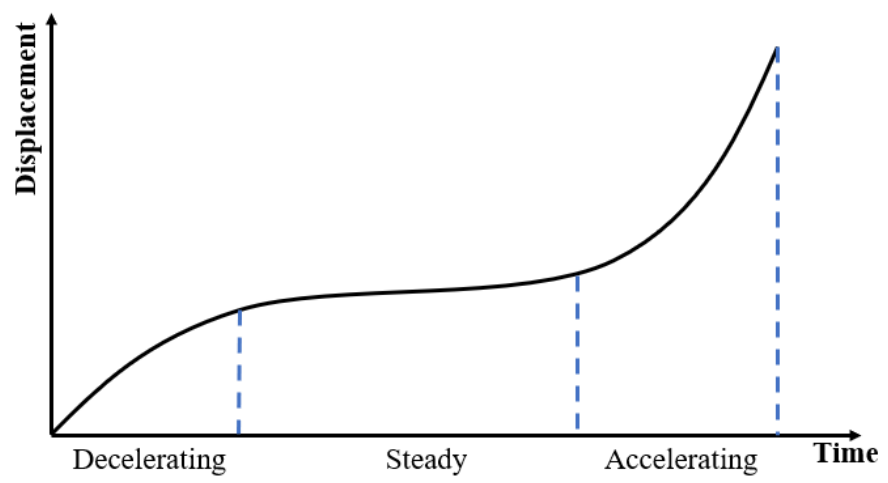

The time series InSAR technique to monitor non-linear ground displacement at millimeter scale over time provides extremely valuable information to characterize not just the susceptibility of the terrain to generate a landslide, but also the type of pre-failure strain that the slope is subject to; decelerating (Fig. 13a); steady (Fig. 13b); or accelerating strains potentially leading to failure (Fig. 13c). The displacement trends of each polygon were checked using the PS Time Series Viewer plugin in QGIS software and, using geomorphological features, were classified manually to ensure accuracy. The pre-failure strain behavior was classified by the displacement trends of pixels in the section with largest displacement rates. Figure 14 shows potential landslides along the edges of the Heitai terrace classified according to these precursory characteristics. The majority of the potential landslides (i.e. $37,1.6 \times 10^{7} \mathrm{~m}^{3}, 83 \%$ of total volume) show steady strains behavior with a constant rate of displacement over the observed period. The displacement rates of 14 potential landslides $\left(2.9 \times 10^{6} \mathrm{~m}^{3}, 14 \%\right.$ of total volume $)$ show signs of accelerating strains. The remaining three potential landslides $\left(0.7 \times 10^{6} \mathrm{~m}^{3}, 3 \%\right.$ of total volume $)$ appear to be decelerating. 

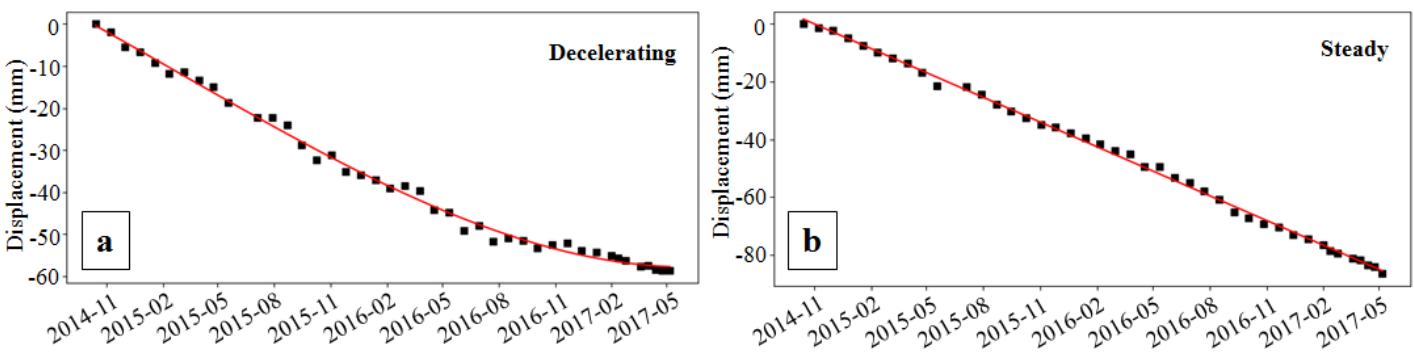

361

362

363

364

365

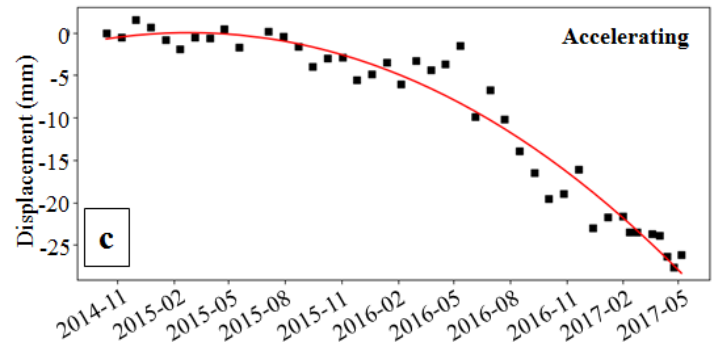

Fig. 13 Typical time-series of three types of pre-failure strain. a) Decelerating, b) steady and c) accelerating strain.

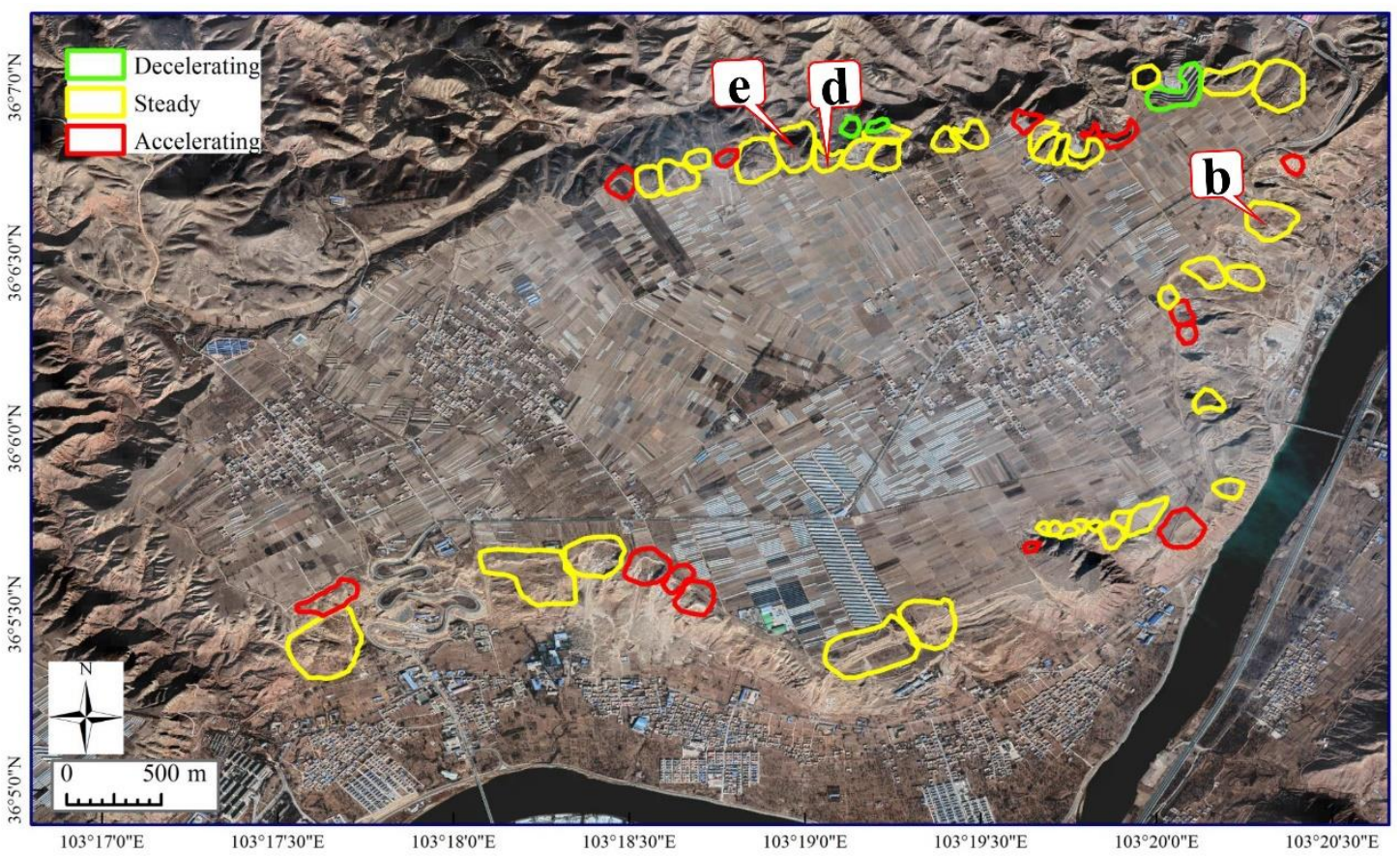

Fig. 14 Pre-failure strain map of potential landslides in Heitai. The colours of outlined polygons indicate the types of strain of potential landslides.

\section{Discussion}

The proposed method provides reliable predictive capability with respect to area and volume of potential landslides at the Heitai river terrace, which are crucial parameters to assess and manage the associated risk. Studies about the empirical relationship between $A_{L}$ and $V_{L}$ are mostly established based on the volume and affected area of landslides (Malamud et al., 2004; Guzzetti et al., 2009; Qiu et al., 2017). Uncertainty in the established relationships can be introduced by local conditions, such as geometry and relief of slip surfaces which represents also a limitation to the 
visibility of spaceborne SAR sensors (Notti et al., 2014) or where InSAR measurements are missing or incomplete because of land cover or displacements larger than the maximum detectable displacement ( $\sim 28 \mathrm{~mm}$ between two consecutive acquisitions for Sentinel-1; Massonnet and Feigl, 1998).

The quality of a landslide inventory is an important factor affecting the reliability of the empirical relationship between $A_{L}$ and $V_{L}$ as mapping accuracy or incomplete inventories can skew the results. The landslide inventory in this study was obtained from literature review; it was updated through the interpretation of remote sensing data with high spatial resolution; and verified through a series of detailed field surveys. The lack of vegetation provided a good environment for the visual recognition of landslide morphology.

Despite the small number of historical landslides in this study (50), the relationship indicates a clear linear trend and self-similar behavior allowing to infer a dependency between $A_{L}$ and $V_{L}$, even if the inventory is incomplete. The relationship is also unaffected by the main types of landslides (loess \& loess-bedrock) and is consistent with those reported by Guzzetti et al. (2009; Table 2 and Fig. 15).

The relationship derived from this study exhibits a trend that is similar to those reported by Guzzetti et al. (2009), but it appears to represent landslides that have slightly larger volumes relative to the ground surface area. This is potentially caused by the dominance of potential landslides occurring along a high terrace edge and a substantial loess thickness (>50 m) influencing the depth of critical slip surfaces and resulting in a landslide population that would be marginally larger than those in more varied terrain.

Table 2 A comparison of 9 empirical relationships reported by Guzzetti et al. (2009) linking landslide area $A_{L}$ to landslide volume $V_{L}$. ID 10 represents the relationship obtained for this study. $\mathrm{N}$ indicates the number of events upon which each relationship is based. These relationships are illustrated in Fig. 15.

\begin{tabular}{|c|c|c|c|c|c|}
\hline ID & Equation & $\begin{array}{c}\operatorname{Min} A_{L} \\
\left(\mathrm{~m}^{2}\right)\end{array}$ & $\begin{array}{c}\operatorname{Max} A_{L} \\
\left(m^{2}\right)\end{array}$ & $\mathrm{N}$ & Source \\
\hline 1 & $\mathrm{~V}_{\mathrm{L}}=0.074 \times \mathrm{A}_{\mathrm{L}}^{1.45}$ & $2.0 \times 10^{0}$ & $1.0 \times 10^{9}$ & 677 & Guzzetti et al. (2009) \\
\hline 2 & $\mathrm{~V}_{\mathrm{L}}=0.1479 \times \mathrm{A}_{\mathrm{L}}^{1.368}$ & $2.3 \times 10^{0}$ & $1.9 \times 10^{5}$ & 207 & Simonett (1967) \\
\hline 3 & $\mathrm{~V}_{\mathrm{L}}=0.1549 \times \mathrm{A}_{\mathrm{L}}^{1.0905}$ & $7.0 \times 10^{2}$ & $1.2 \times 10^{5}$ & 124 & $\begin{array}{r}\text { Guthrie and Evans } \\
\text { (2004) }\end{array}$ \\
\hline 4 & $\mathrm{~V}_{\mathrm{L}}=0.39 \times \mathrm{A}_{\mathrm{L}}^{1.31}$ & $1.0 \times 10^{1}$ & $3.0 \times 10^{3}$ & 51 & $\begin{array}{r}\text { Imaizumi and Sidle } \\
\text { (2007) }\end{array}$ \\
\hline 5 & $\mathrm{~V}_{\mathrm{L}}=0.0844 \times \mathrm{A}_{\mathrm{L}}^{1.4324}$ & $1.0 \times 10^{1}$ & $1.0 \times 10^{9}$ & 539 & Guzzetti et al. (2008) \\
\hline 6 & $\mathrm{~V}_{\mathrm{L}}=0.19 \times \mathrm{A}_{\mathrm{L}}^{1.19}$ & $5.0 \times 10^{1}$ & $4.0 \times 10^{3}$ & 11 & Imaizumi et al. (2008) \\
\hline
\end{tabular}




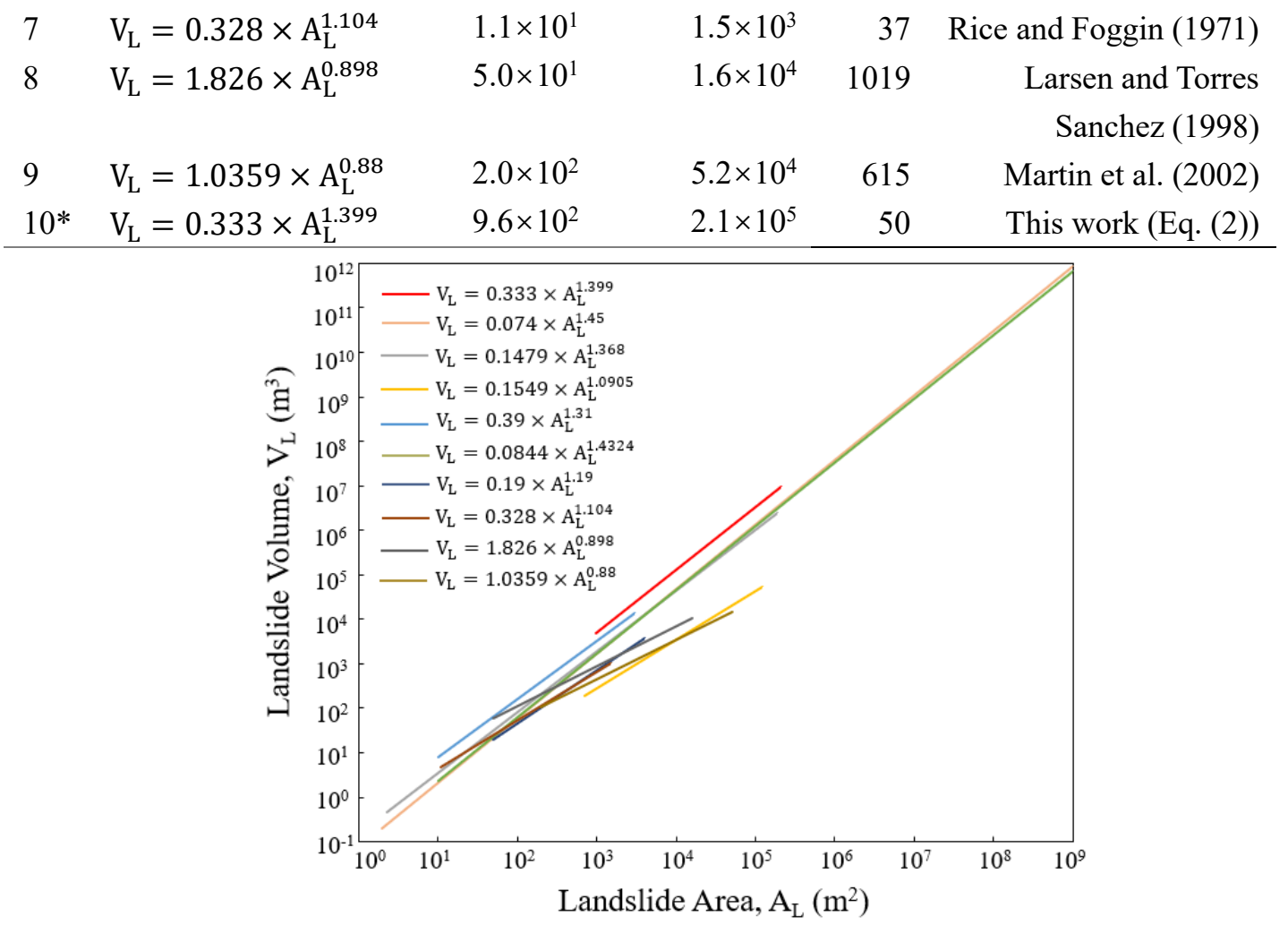

Fig. 15 Empirical relationships linking landslide area $\left(\mathrm{A}_{\mathrm{L}}\right)$ and volume $\left(\mathrm{V}_{\mathrm{L}}\right)$ proposed in Guzzetti et al. (2009) and in this study (red line).

The mapping of potential landslides is based on a combination of an InSAR-derived 403 from field mapping and literature review. Different time series InSAR techniques are applicable to different environments and objectives of research (Hooper et al., 2012; Wasowski \& Bovenga, 2014).

405 A sufficient density of CTs, which depends on the number and quality of images, temporal distribution and extent of data, characteristic of physical processes, CT detecting method and 407 processing technique (Wasowski and Bovenga, 2014), can be used as support to distinguish the 408 boundary of potential landslides. In addition, understanding the topography and mechanisms of 409 geomorphological processes in the study area is vital, e.g. to improve identification and characterization of active slopes. 

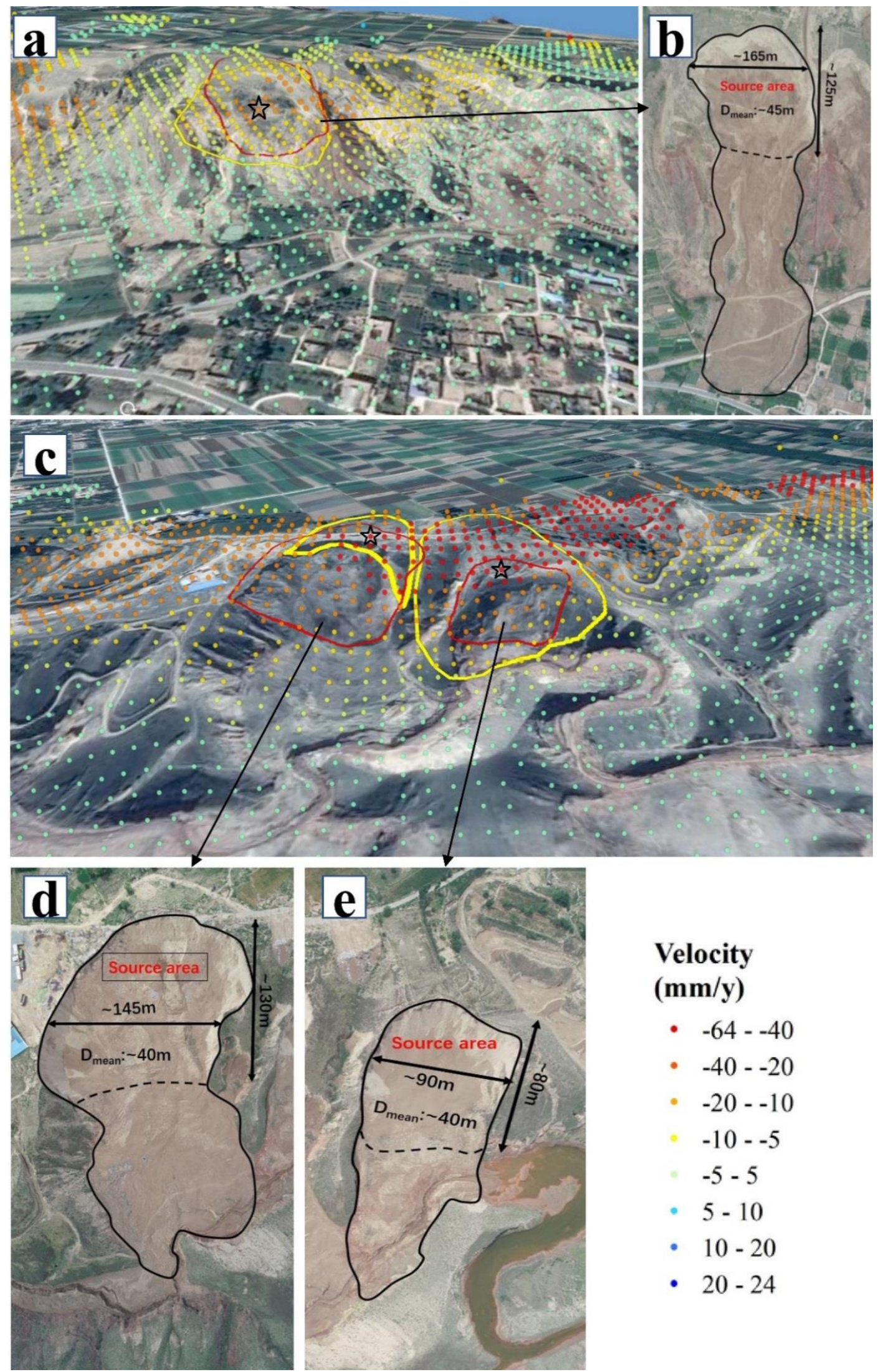

\section{Velocity (mm/y)}

- $-64--40$

- $-40--20$

- $-20--10$

$-10--5$

$-5-5$

- $5-10$

- $10-20$

- 20-24

Fig. 16 Three landslides with Google earth image (a \& c) in 3D ArcGlobe and photograph (b, d \& e) as background. Yellow outlines indicate the forecasted source area of landslides, red outlines indicate the source area of landslides occurred after 5 February 2019, the black outlines indicate the affected area of 
landslides. The geometrical properties of landslides were measured by Laser Rangefinder in the field. The Google Earth image was acquired on 5 February 2019. The photographs were taken by UAV on 17 June 2019. The locations of b, $d$ and e are show in Fig. 14. The black outlined stars indicate the location of InSAR time-series displacement in Fig. 17 for landslide in b, d \& e.

The validation of the forecasted magnitude of potential landslides was further enhanced following three case studies of events that occurred soon after InSAR monitoring from $14^{\text {th }}$ October 2014 to $7^{\text {th }}$ May 2017. The geometrical and geomorphological characteristics of these three landslides were established using a Laser Rangefinder in the field (Fig. 16). The landslides shown in Fig. 16 are a re-activation of an existing landslide (16b), a re-activation of the crown area of an existing landslide (16d), and a new landslide (16e) respectively. The volume of the landslides was calculated as the product of the length, width and mean depth multiplied by a correction factor that depends on the geometry of the event. For a landslide occurring on a natural slope without previous slope failures, the coefficient is 0.5 (Figs. $16 \mathrm{~b}$ and 16e). The correction factor is taken as 0.3 where a landslide occurs on the backscarp and overlaps with previous landslide deposits (Fig. 16d). The volume of the three landslides in Fig. $16 \mathrm{~b}$, $\mathrm{d}$ and e are $55.7 \times 10^{4} \mathrm{~m}^{3}, 22.6 \times 10^{4} \mathrm{~m}^{3}$ and $17.3 \times 10^{4} \mathrm{~m}^{3}$ compared to corresponding forecasted volumes of $66.7 \times 10^{4} \mathrm{~m}^{3}, 14.5 \times 10^{4} \mathrm{~m}^{3}$ and $72.5 \times 10^{4} \mathrm{~m}^{3}$. This shows a good consistence between the forecasted and actual landslide volume with a small overestimation of volume for the landslide shown in Fig. 16b. Figure 16d indicates that our empirical method only slightly underestimated the actual landslide volume. The actual landslide in Fig. 16e is located within the forecasted area, but did not manifest an event (as yet) that is as large as the forecasted size. It can be concluded therefore, that the applied method of forecasting the location and magnitude of potential landslides can provide an adequate insight into where the greatest risk is located providing a useful guide to assist with the management of these geohazards.

The three landslides shown in Fig. 16 have a similar geometry of the sliding surface; the landslides develop largely within the loess deposits and contain only small amounts of bedrock. This corresponds well with the assumption used for the identification of potential landslides in this study. In the field survey that was carried out before these landslides occurred, large cracks were observed along the upper margin of the potential landslide of Fig. 16e. However, there were no apparent cracks observed that would indicate the position of the backscarps of the landslides in Fig. $16 \mathrm{~b}$ and $16 \mathrm{~d}$. This supports the value of using CTs for the identification of potential landslides, and that further evidence from geomorphological features (trends of cracks, sinkholes, valleys and 
ridges) can then provide added value for determining the extent of these potential events.
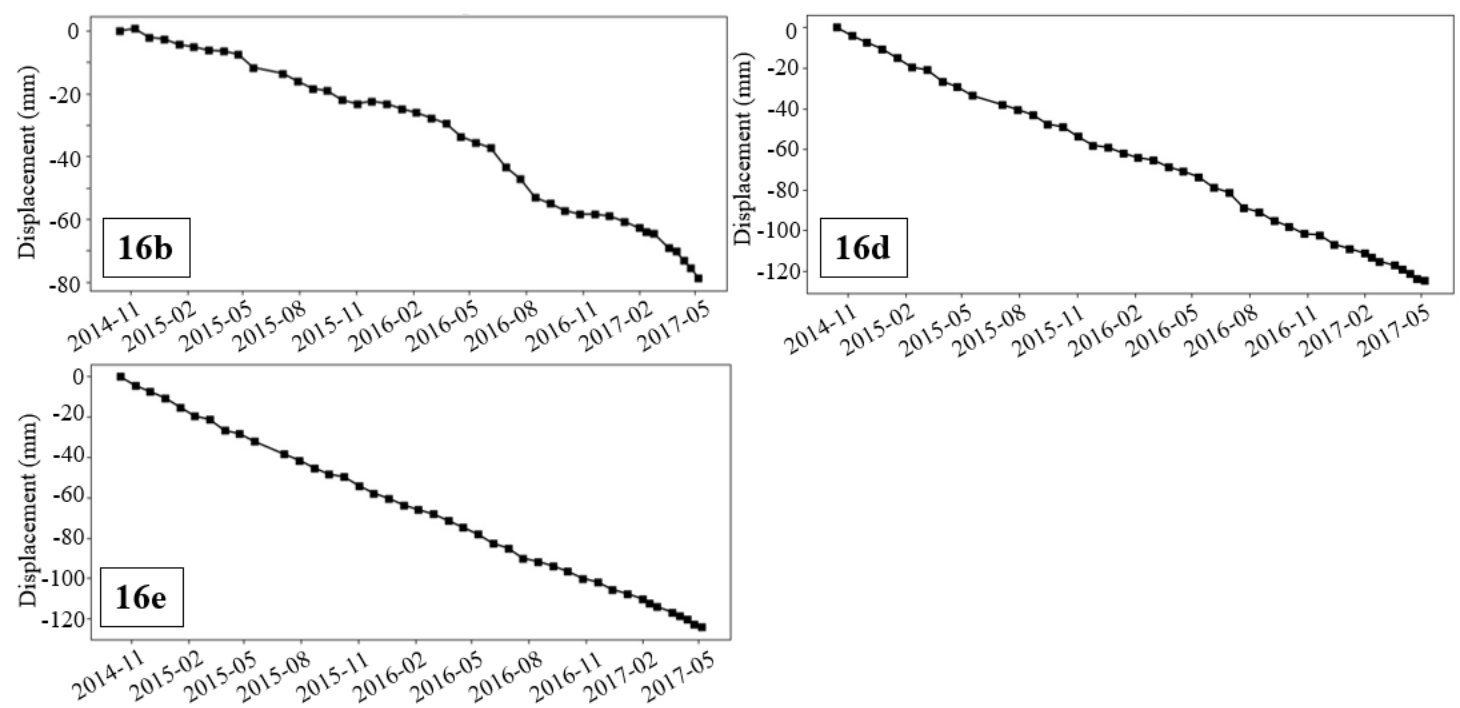

Fig. 17 Time-series displacement from $14^{\text {th }}$ October 2014 to $7^{\text {th }}$ May 2017 for landslides shown in Fig. $16 \mathrm{~b}, 16 \mathrm{~d}$ and $16 \mathrm{e}$.

Figure 17 shows the time-series displacements for landslides in Fig. 16. Interestingly, landslides in Fig. 16d and 16e show steady strains from October 2014 to May 2017, and landslide in Fig. 16b shows accelerating strains after February 2016. In Fig.17(16b), the acceleration occurred from February 2016 to September 2016 and February 2017 to May 2017, which is consistent with intensive irrigation activities in early Spring and corresponds with the timings of most landslides along the Heitai terrace. These three examples therefore provide a clear indication that extrapolating strain rates to obtain a time to failure must be used with great caution.

The combination of InSAR and an empirical model not only extends their application, but also provides an important contribution towards the quantification of landslide risk assessment. The landslide volume that is determined using this approach enables estimation of the magnitude of potential landslides. Coupled with observations on the typical sliding velocity and runout distance of landslides in this region, in the near-future this could provide estimates of exposure to these hazards and improvements in risk reduction strategies for this region. Opportunities to estimate the probability of landslide occurrence will enhance as the InSAR time-series analysis accumulates. This study has shown that this is a plausible pathway to determine the magnitude of potential landslides in this region. It also highlights that further work is required to establish (semi-)empirical or physical models to evaluate the full potential of using time-series displacement generated by InSAR to predict the occurrence (time, place, size) of landslides (Saito, 1969; Petley et al., 2005; Serena et al., 2017). Further analysis of these time-series displacement profiles of individual 
(potential) events can help to direct monitoring and observation resources to sites that are in an accelerating strain phase and help to highlight areas at risk that may require preventative evacuation. With time, this can result in a regional approach that addresses landslides hazard management throughout this part of the Loess Plateau and other similar regions.

\section{Conclusions}

An empirical model linking landslide area to volume was combined with an evaluation of time series InSAR to construct a method to forecast the location, area and volume of potential landslides in the Heitai terrace region of central Gansu Province, China.

An inventory of 50 historical landslides was used to generate the empirical relationship $\left(\mathrm{V}_{\mathrm{L}}=\right.$ $0.333 \times \mathrm{A}_{\mathrm{L}}^{1.399}$ ), which is in good agreement with similar relationships established elsewhere (Guzzetti et al. 2009). The total area and volume of historical landslides are $1.26 \times 10^{6} \mathrm{~m}^{2}$ and $3.86 \times 10^{7} \mathrm{~m}^{3}$, respectively. The magnitude of these historical landslides is expressed as the base 10 logarithm of the landslide volume and varies from 3 to 6 .

42 Sentinel 1 images acquired from $14^{\text {th }}$ October 2014 to $7^{\text {th }}$ May 2017 were processed by SBAS technique to generate the ground displacement rates to support the identification and mapping of potential landslides. A total of 157,434 CTs (2399 CTs km$\left.{ }^{-2}\right)$ with displacement rates between 24 $\mathrm{mm} / \mathrm{y}$ and $-64 \mathrm{~mm} / \mathrm{y}$ were detected around the Heitai terrace. Fifty-four potential landslides were identified using the stability threshold of $\pm 10 \mathrm{~mm} / \mathrm{y}$ and further refined using geomorphological interpretation.

Finally, the areas of these 54 potential landslides were mapped by time series InSAR and their volumes $\left(\mathrm{V}_{\mathrm{P}}\right)$ were calculated using the empirical relationship. Before $7^{\text {th }}$ May 2017,16 potential landslides are identified with volumes in the range $1.29 \times 10^{4} \mathrm{~m}^{3} \leq \mathrm{V}_{\mathrm{P}} \leq 10 \times 10^{4} \mathrm{~m}^{3}, 32$ potential landslides with volumes in the range $1 \times 10^{5} \mathrm{~m}^{3}<\mathrm{V}_{\mathrm{P}} \leq 10 \times 10^{5} \mathrm{~m}^{3}, 6$ potential landslides with volumes in the range $1 \times 10^{6} \mathrm{~m}^{3}<\mathrm{V}_{\mathrm{P}} \leq 4.27 \times 10^{6} \mathrm{~m}^{3}$.

The approach of this study enabled identification of location, area and volume of potential landslides in the Heitai terrace. The magnitude of these potential landslides (an expression based on the base 10 logarithm of landslide volume) helps to convey the severity of these events, were they to occur. Once the InSAR-based displacement time-series becomes longer, it is anticipated that analyses of the patterns of pre-failure strains will provide further insights into forecasting time to 
failure. The further development of effective landslide risk management in this region will benefit from this approach as it will provide the best available knowledge to characterize the location and size of a potential event. With careful analysis of the pattern of pre-failure strains this combined knowledge will be instrumental in designing appropriate management and mitigation strategies. The information also enables assessment of the potential for post-failure mobility and the modeling of landslide runout. In turn this enables designation of zones at risk from these potential landslides in the Heitai region and this will be reported in a separate paper.

Extending this method over a larger area in this part of the Loess Plateau will enhance the quality of the landslide inventory and fine-tune the empirical relationship. The landslides in the Heitai area generally occur entirely within the loess deposits, with the deepest slip surfaces positioned along the loess-bedrock interface. This rule of thumb works well in this region and it is reasonable to assume that this can also be applied in many other parts of the $440,000 \mathrm{~km}^{2}$ large Loess Plateau or areas elsewhere where such clear distinctions in surface strata and underlying bedrock exist. This method has the potential to generate very useful information across a much larger regions that will benefit landslide risk assessment, hazard management, and research on landscape evolution.

\section{Acknowledgements}

This study was supported by National Key Research and Development Program of China (Grant Nos. 2018YFC1504704 and 2017YFC1501005) and National Natural Science Foundation of China (Grant Nos. 41702292, 41602348) and Science and Technology Major Project of Gansu Province (Grant Nos. 19ZD2FA002) and the Fundamental Research Funds for the Central Universities (Grant Nos. lzujbky-2019-28). The Sentinel 1 images and precise orbits were provided by the European Space Agency. We thank NASA for providing the SRTM1 DEM data and Dr R. Ciurean for her valuable suggestions. Colm Jordan and Alessandro Novellino publish with permission of the Executive Director, BGS, with support from the BGS ODA Programme. We are grateful to associate editor (Joseph Awange) and three anonymous reviewers for their detailed comments.

\section{References}

1. Ambrosi, C., Strozzi, T., Scapozza, C., Wegmüller, U., 2018. Landslide hazard assessment in the Himalayas (Nepal and Bhutan) based on Earth-Observation data. Eng. Geo. 237, 217-228.

2. Berardino, P., Fornaro, G., Lanari, R., \& Sansosti, E., 2002. A new algorithm for surface deformation monitoring based on small baseline differential SAR interferograms. IEEE Trans. Geosci. Remote Sens. 40, 2375-2383.

3. Broeckx, J., Vanmaercke, M., Duchateau, R., \& Poesen, J., 2018. A data-based landslide susceptibility map of Africa. Earth-Science Reviews, 185, 102-121. 
4. Carlà, T., Intrieri, E., Raspini, F., Bardi, F., Farina, P., Ferretti, A., Colombo, D., Novali, F., Casagli, N., 2019. Perspectives on the prediction of catastrophic slope failures from satellite InSAR. Sci. Rep. 9, 14137. https://doi.org/10.1038/s41598-019-50792-y.

5. Chen, Q., Cheng, H., Yang, Y., Liu, G., Liu, L., 2014. Quantification of mass wasting volume associated with the giant landslide Daguangbao induced by the 2008 Wenchuan earthquake from Persistent Scatterer InSAR. Remote Sens. Environ. 152, 125-135.

6. Cigna, F., Bianchini, S., Casagli, N., 2013. How to assess landslide activity and intensity with Persistent Scatterer Interferometry (PSI): the PSI-based matrix approach. Landslides 10, 267-283.

7. Corominas, J., Westen, C., Frattini, P., Cascini, L., Smith, J., 2014. Recommendations for the quantitative analysis of landslide risk. Bull. Eng. Geo. Environ. 73, 209-263.

8. Crosta G., Frattini P, Agliardi F., 2013. Deep seated gravitational slope deformations in the European Alps. Tectonophysics 605:13-33.

9. Cruden D., Varnes D., 1996. Landslide Types and Processes. Special Report - National Research Council, Transportation Research Board 247:36-75.

10. Cui, Y., Deng, J., Xu, C., 2018. Volume estimation and stage division of the Mahu landslide in Sichuan Province, China. Natural Hazards 93: 941-955.

11. Dai F., Lee C., Ngai Y., 2002. Landslide risk assessment and management: an overview. Eng. Geol. 64:65-87.

12. Dijkstra, T, Rogers, C., Smalley, I., Derbyshire, E., Li, Y., Meng, X., 1994. The loess of north-central China: geotechnical properties and their relation to slope stability. Eng. Geol. 36, 153-171.

13. Federico, A., Popescu, M., Elia, G., Fidelibus, C., G. Internò, Murianni, A., 2012. Prediction of time to slope failure: a general framework. Environ. Earth Sci. 66, 245-256.

14. Ferretti, A., Montiguarnieri, A., Prati, C., Rocca, F., Massonet, D., 2007. InSAR principles - guidelines for SAR interferometry processing and interpretation. J. Finan. Stab. 10, 156-162.

15. Ferretti, A., Prati, P., Rocca, F., 2001. Permanent Scatterers in SAR Interferometry. IEEE Trans. Geosci. Remote Sens. 39, 8-20.

16. Froude, M., Petley, D., 2018. Global fatal landslide occurrence from 2004 to 2016. Nat. Hazards Earth Syst. Sci. 18, 2161-2181.

17. Guo, P., Meng, X., Li, Y., Chen, G., Zeng, R., Qiao, L., 2015. Effect of large dams and irrigation in the upper reaches of the Yellow River of China, and the geohazards burden. Proc. Geol. Assoc. 126, 367-376.

18. Guthrie, R., Evans, S., 2004. Analysis of landslide frequencies and characteristics in a natural system, coastal British Columbia. Earth Surf. Process. Landf. 29, 1321-1339.

19. Guzzetti, F., Reichenbach, P., Cardinali, M., Galli, M., Ardizzone, F., 2005. Probabilistic landslide hazard assessment at the basin scale. Geomorphology. 72, 272-299.

20. Guzzetti, F., Ardizzone, F., Cardinali, M., Rossi, M., Valigi, D., 2009. Landslide volumes and landslide mobilization rates in Umbria, central Italy. Earth Planet. Sci. Lett. 279, 222-229.

21. Hanssen, R. F., 2001. Radar interferometry: data interpretation and error analysis (Vol. 2). Springer Science \& Business Media.

22. Herrera, G., Gutiérrez, F., García-Davalillo, J., Guerrero, J., Notti, D., Galve, J., Fernández-Merodo, J. Cooksley, G., 2013. Multi-sensor advanced DInSAR monitoring of very slow landslides: The Tena Valley case study (Central Spanish Pyrenees). Remote Sens. Environ. 128, 31-43.

23. Hooper, A., Bekaert, D., Spaans, K., Arıkan, M., 2012. Recent advances in SAR interferometry time series analysis for measuring crustal deformation. Tectonophysics 514, 1-13.

24. Hungr, O., Leroueil, S., Picarelli, L., 2014. The Varnes classification of landslide types, an update. Landslides 11, 167-194. 
25. Imaizumi, F., Sidle, R., 2007. Linkage of sediment supply and transport processes in Miyagawa Dam catchment, Japan. J. Geophys. Res. 112.

26. Imaizumi, F., Sidle, R., Kamei, R., 2008. Effects of forest harvesting on the occurrence of landslides and debris flows in steep terrain of central Japan. Earth Surf. Process. Landf. 33, 827-840.

27. Intrieri, E., Carlà, T., \& Gigli, G., 2019. Forecasting the time of failure of landslides at slope-scale: A literature review. Earth-science reviews 193, 333-349.

28. Klar, A., Aharonov, E., Kalderon-Asael, B., Katz, O., 2011. Analytical and observational relations between landslide volume and surface area. J. Geophys. Res. Earth Surf. 116.

29. Larsen, M.C., Torres Sanchez, A.J., 1998. The frequency and distribution of recent landslides in three montane tropical regions of Puerto Rico. Geomorphology 24, 309-331.

30. Leroueil, S., 2001. Natural slopes and cuts: movement and failure mechanisms. Géotechnique 51, 197-243.

31. Li, M., Zhang, L., Ding, C., Li, W., Luo, H., Liao, M., Xu, Q., 2020. Retrieval of historical surface displacements of the Baige landslide from time-series SAR observations for retrospective analysis of the collapse event. Remote Sens. Environ. 240, https://doi.org/10.1016/j.rse.2020.111695.

32. Malamud, B., Turcotte, D., Guzzetti, F., Reichenbach, P., 2004. Landslide inventories and their statistical properties. Earth Surf. Process. Landf. 29, 687-711.

33. Martha, T., van Westen, C., Kerle, N., Jetten, V., Kumar, K., 2013. Landslide hazard and risk assessment using semi-automatically created landslide inventories. Geomorphology 184, 139-150.

34. Martin, Y., Rood, K., Schwab, J. W., Church, M., 2002. Sediment transfer by shallow landsliding in the Queen Charlotte Islands, British Columbia. Canadian J. Earth Sci. 39, 189-205.

35. Massonnet, D., Feigl, K., 1998, Radar interferometry and its application to changes in the Earth's surface, Rev. Geophys. 36, 441- 500.

36. Notti, D., Herrera, G., Bianchini, S., Meisina, C., García-Davalillo, J., Zucca, F., 2014. A methodology for improving landslide PSI data analysis. Int. J. Remote Sens. 35, 2186-2214.

37. Novellino, A., Cigna, F., Sowter, A., Ramondini, M., Calcaterra, D., 2017. Exploitation of the intermittent SBAS (ISBAS) algorithm with COSMO-SKYMED data for landslide inventory mapping in north-western Sicily, Italy. Geomorphology 280, 153-166.

38. Osmanoğlu, B., Sunar, F., Wdowinski, S., Cabral-Cano, E., 2016. Time series analysis of InSAR data: Methods and trends. ISPRS J. Photogram. Remote Sens. 115, 90-102.

39. Peng, D., Xu, Q., Qi, X., Fan, X., Dong, X., Li, S., Ju, Y., 2016. Study on early recognition of loess landslides based on field investigation. Int. J. Geor. Environ. (formerly Int'l J Geohazards Environ.) 2, 35-52.

40. Peng, D., Xu, Q., Liu, F., He, Y., Zhang, S., Qi, X., Zhao K., Zhang X., 2017. Distribution and failure modes of the landslides in Heitai terrace, China. Eng. Geol. 236, 97-110.

41. Petley, D., Higuchi, T., Petley, D., Bulmer, M., Carey, J., 2005. Development of progressive landslide failure in cohesive materials. Geology 33, 201-204.

42. Qiu, H., Cui, P., Regmi, A., Hu, S., Wang, X., Zhang, Y., He, Y., 2017. Influence of topography and volume on mobility of loess slides within different slip surfaces. Catena 157, 180-188.

43. Rice, R. M., Iii, G. T. F., 1971. Effect high intensity storms on soil slippage on mountainous watersheds in southern California. Water Resour. Res. 7, 1485-1496.

44. Saito, M., 1969. Forecasting time of slope failure by tertiary creep. In Proc. 7th Int. Conf. Soil Mechanics and Foundation Eng. Mexico City, 2, 677-683.

45. Serena, M., Francesca, B., Carlo, E., Paolo, M., Alfredo, R., 2017. Assessment of landslide pre-failure monitoring and forecasting using satellite SAR Interferometry. Geosciences 7, 36. 
46. Shi, X., Xu, Q., Zhang, L., Zhao, K., Dong, J., Jiang, H., Liao, M., 2019. Surface displacements of the Heifangtai terrace in Northwest China measured by X and C-band InSAR observations. Eng. Geol. 259, 105181. https://doi.org/10.1016/j.enggeo.2019.105181

47. Simonett, D. S., 1967. Landslide distribution and earthquakes in the Bavani and Torricelli mountains, New Guinea. Landform Studies from Australia and New Guinea 64-84.

48. Tseng, C., Lin, C., Stark, C., Liu, J., Fei, L., Hsieh, Y., 2013. Application of a multi-temporal, LiDAR-derived, digital terrain model in a landslide-volume estimation. Earth Surf. Process. Landf. 38, 1587-1601.

49. Voight, B., Orkan, N., Young, K., 1989. Deformation and failure-time prediction in rock mechanics. In The 30th US Symposium on Rock Mechanics (USRMS). American Rock Mechanics Association.

50. Wasowski, J., Bovenga, F., 2014. Investigating landslides and unstable slopes with satellite multi temporal interferometry: current issues and future perspectives. Eng. Geol. 174, 103-138.

51. Xu, L., Dai, F., Kwong, A., 2008. Types and characteristics of loess landslides at Heifangtai loess plateau, china. J. Mount. Sci. 26, 364-371.

52. Xu, L., Dai, F., Tu, X., Tham, L., Zhou, Y., Iqbal, J., 2014. Landslides in a loess platform, North-West China. Landslides 11, 993-1005.

53. Zeng, R., Meng, X., Zhang, F., Wang, S., Cui, Z., Zhang, M., Zhang, Y., Chen G., 2016. Characterizing hydrological processes on loess slopes using electrical resistivity tomography - a case study of the Heifangtai terrace, northwest China. J. Hydrol. 541, 742-753.

54. Zhang, F., Wang, G., 2017. Effect of irrigation-induced densification on the post-failure behavior of loess flowslides occurring on the Heifangtai area, Gansu, China. Eng. Geol. 236, 111-118.

55. Zhang, Y., Meng, X., Jordan, C., Novellino, A., Dijkstra, T., Chen, G., 2018. Investigating slow-moving landslides in the Zhouqu region of china using InSAR time series. Landslides 15:1299-1315.

56. Zhuang, J., Peng, J., Xu, C., Li, Z., Densmore, A., Milledge, D., Iqbal, J., Cui, Y., 2018. Distribution and characteristics of loess landslides triggered by the 1920 Haiyuan Earthquake, Northwest of China. Geomorphology 314, 1-12.

\section{List of Figure Captions}

Fig. 1 Workflow for the evaluation of the magnitude of potential landslides at the Heitai terrace, Gansu, China. An initial field survey was employed to verify the boundaries of landslides. Further field surveys enabled validation of the empirical model.

Fig. 2 The Heitai study area (top) and landslides inventory map (bottom). Red line (AA') indicates the location of the geological profile in Fig. 3. The background is Google Earth imagery.

Fig. 3 Geological cross-section of Heitai terrace. The locations are shown in Fig. 2 (line AA'). (modified from Peng et al., 2016)

Fig. 4 Spatial-temporal distribution of interferogram formation. Green dots and black lines represent images and interferometric pairs, respectively. The yellow dot in the red circle is the master image used for the co-registration.

Fig. 5 Empirical model for landslides obtained through a literature review and field survey. Dots portray the area, $A_{L}\left(x\right.$-axis, $\mathrm{m}^{2}$ ), and volume, $V_{L}\left(y\right.$-axis, $\mathrm{m}^{3}$ ), of 50 landslides. The solid red line represents the best fit obtained, adopting a least square linear fitting technique. Dashed red lines show 95\% confidence intervals. Colours indicate density of points obtained through bivariate kernel density estimation.

Fig. 6 (Left) Conceptual diagram of typical Heitai landslide where the red line is the outline of the landslide and includes the source and depositional areas. (Right) A schematic section through a landslide showing the original slope profile, the post-event slope and the assumed position of the slip surface.

Fig. 7 Mean displacement rates estimated by SBAS and demonstrated by field survey for cracks and 
scarps investigation. Photographs on the top and below are cracks and scarps along the edge of terrace. Fig. 8 Potential landslides mapped based on displacement rate map. The background is Google Earth imagery.

Fig. 9 Displacement rates of potential landslides in Heitai terrace. The colours of outlined polygons indicate the mean LOS velocity of CTs inside the polygon. The background is Google Earth imagery. Fig. 10 The volume of potential landslides calculated based on empirical relationship. The colours of polygons indicate the volume and magnitude of potential landslides.

670 Fig. 11 Landslide volume versus landslide rank. The column colour corresponds to landslide volume 671 classes shown in Fig. 10.

672 Fig. 12 Idealized pre-failure strain model

673 Fig. 13 Typical time-series of three types of pre-failure strain. a) Decelerating, b) steady and c) 674 accelerating strain.

675 Fig. 14 Pre-failure strain map of potential landslides in Heitai. The colours of outlined polygons

676 indicate the types of strain of potential landslides.

677 Fig. 15 Empirical relationships linking landslide area $\left(\mathrm{A}_{\mathrm{L}}\right)$ and volume $\left(\mathrm{V}_{\mathrm{L}}\right)$ proposed in Guzzetti et al. 678 (2009) and in this study (red line).

679 Fig. 16 Three landslides with Google earth image (a \& c) in 3D ArcGlobe and photograph (b, d \& e) as 680 background. Yellow outlines indicate the forecasted source area of landslides, red outlines indicate the 681 source area of landslides occurred after 5 February 2019, the black outlines indicate the affected area of 682 landslides. The geometrical properties of landslides were measured by Laser Rangefinder in the field. 683 The Google Earth image was acquired on 5 February 2019. The photographs were taken by UAV on 17 684 June 2019. The locations of $b, d$ and e are show in Fig. 14. The black outlined stars indicate the location 685 of InSAR time-series displacement in Fig. 17 for landslide in b, $\mathrm{d} \&$ e.

686 Fig. 17 Time-series displacement from $14^{\text {th }}$ October 2014 to $7^{\text {th }}$ May 2017 for landslides shown in Fig. 687 $16 \mathrm{~b}, 16 \mathrm{~d}$ and $16 \mathrm{e}$. 